\title{
ANALYTICAL DESCRIPTIONS OF DYNAMIC SOFTENING MECHANISMS FOR Ti-13Nb-13Zr BIOMEDICAL ALLOY IN SINGLE PHASE AND TWO PHASE REGIONS
}

\begin{abstract}
Dynamic softening behaviors of a promising biomedical Ti-13Nb-13Zr alloy under hot deformation conditions across dual phase $\alpha+\beta$ and single phase $\beta$ regions were quantitatively characterized by establishing corresponding dynamic recovery (DRV) and dynamic recrystallization (DRX) kinetic models. A series of wide range hot compression tests on a Gleeble-3500 thermo-mechanical physical simulator were implemented under the strain rate range of $0.01-10 \mathrm{~s}^{-1}$ and the temperature range of 923-1173 K. The apparent differences of flow stress curves obtained in dual phase $\alpha+\beta$ and single phase $\beta$ regions were analyzed in term of different dependence of flow stress to temperature and strain rate and different microstructural evolutions. Two typical softening mechanisms about DRV and DRX were identified through the variations of a series of stress-strain curves acquired from these compression tests. DRX is the dominant softening mechanism in dual phase $\alpha+\beta$ range, while DRV is the main softening mechanism in single phase $\beta$ range. The DRV kinetic model for single phase $\beta$ region and the DRX kinetic model for dual phase $\alpha+\beta$ region were established respectively. In addition, the microstructures of the compressed specimens were observed validating the softening mechanisms accordingly.

Keywords: Biomedical titanium alloy, Flow stress, Dynamic recovery, Dynamic recrystallization, Dynamic softening
\end{abstract}

\section{Introduction}

Titanium (Ti) and its alloys are nowadays the most attractive metallic biomaterials in contrast to the ceramic and polymeric biomaterials which possess poor mechanical properties [1,2]. In the early age, Ti-6Al-4V and Ti-6Al-7Nb alloys had been applied to replace other alloy systems because of their high strength to weight ratio, superior biocompatibility and corrosion resistance, good mechanical properties and low elastic modulus [3]. However, these alloys are demonstrated unsuitable for biomedical applications due to the toxic effect of both $\mathrm{Al}$ and $\mathrm{V}$ $[4,5]$. Thus, the $\beta$ titanium alloy Ti-13Nb-13Zr was developed and has been proved to be well suited for surgical implant such as artificial spines, artificial thighbones and hip joints, etc., which are used under fatigue conditions. The fatigue property of a material largely depends on the microstructures obtained by heat treatment or thermomechanical treatment. Hot deformation is an effective thermomechanical treatment method for the improvement of strength-ductility balance by proper refinement of alloy microstructures, which significantly improves the quality of life of the recipients.

In the last few decades, extensive studies have been carried out to describe the hot deformation behavior of titanium alloys [6-10]. During the hot deformation, multiple dynamic softening mechanisms such as dynamic recovery (DRV), dynamic recrys- tallization (DRX), meta-dynamic recrystallization (MDRX) and dynamic strain induced transformation (DSIT) may take place, and the grains can be refined or homogenized [11]. These mechanisms produce strain-softening that neutralizes the work hardening due to the new dislocation formation in plastic deformation proceeding. The result is the global stress diminution. The deep understanding of the fundamental softening mechanisms is a prerequisite for achieving desired microstructures of final part in deformation processing. The modeling of softening kinetics is of special importance in forming processes because any feasible mathematical simulation needs accurate description of the underlying plastic deformation behavior.

A few reported works have associated the work-hardening and dynamic strain-softening behaviors with relative deformation mechanisms for metallic materials [12-14]. Work-hardening and dynamic softening effects have been considered interdependent due to the fact that the driving force for dynamic softening is provided by distortion energy from work-hardening process, meanwhile the softening effect makes the continuous strain extending possible to induce subsequent hardening [15]. There exists dynamic competitive procedure between the work-hardening resulting from dislocation reduplication, pileup and tangle, and the softening resulting from the DRV and DRX [16].

Cui et al. [17] investigated the hot deformation behavior of Ti-6Al-7Nb in two-phase $\alpha+\beta$ region. Momeni et al. [10]

\footnotetext{
* STATE KEY LABORATORY OF MECHANICAL TRANSMISSION, SCHOOL OF MATERIAL SCIENCE AND ENGINEERING, CHONGQING UNIVERSITY, CHONGQING 400044, CHINA

** STATE KEY LABORATORY OF MATERIALS PROCESSING AND DIE \& MOULD TECHNOLOGY, HUAZHONG UNIVERSITY OF SCIENCE AND TECHNOLOGY, HUBEI 430074, CHINA 
analyzed different microstructural evolutions through flow stress curves obtained via conducting hot compression tests of Ti-6Al-4V alloy in dual phase $\alpha+\beta$ and single phase $\beta$ regions. Warchomicka et al. [9] indicated that DRV and DRX of $\beta$ phase were also responsible for the flow softening of a near $\beta$ titanium alloy, Ti-5Al-5Mo-5V-3Cr-1Zr. Ning et al. [15] constructed segmented functions to describe the competition between DRV and DRX during hot deformation for TC18 (Ti-5Al-5Mo-5V$1 \mathrm{Cr}-1 \mathrm{Fe}$ ) titanium alloy. Quan et al. [18] quantitatively analyzed the dynamic softening behaviors induced by DRX by combining Johnson-Mehl-Avrami-Kolmogorov (JMAK) kinetics equation with work-hardening $(\theta=\partial \sigma / \partial \varepsilon)$ characteristics for Ti-10V2Fe-2Al Alloy. on the experimental front, dynamic softening behaviors for metallic materials during hot deformation has been studied before, but quite rare studies have been found in the literature on modeling the softening kinetics of Ti-Nb-Zr alloys during hot deformation across dual phase $\alpha+\beta$ and single phase $\beta$ regions. Lin et al. [19] improved the classical dislocation density-based models to characterize the hot deformation behaviors and grain size evolution.

The aim of present research is to investigate different dynamic softening behaviors of Ti-13Nb-13Zr Alloy via isothermal compression tests performed across dual phase $\alpha+\beta$ and single phase $\beta$ regions. Through the further analysis of the stress-strain curve variation under different deformation conditions, different dominant softening mechanisms of DRV, DRX were identified for single phase $\beta$ and dual phase $\alpha+\beta$ regions, which were verified by metallographic analysis. Different from other previous investigations, the present investigation has been carried out in order to develop a general methodology that could be employed to conduct a rational analysis and modeling of the different dominant softening mechanisms for titanium alloys hot-worked in single phase $\beta$ and dual phase $\alpha+\beta$ regions, that is the DRV kinetic model for single phase $\beta$ region and the DRX kinetic model for dual phase $\alpha+\beta$ region.

\section{Experimental procedures}

The material investigated in this work is as-rolled Ti-13Nb$13 \mathrm{Zr}$ alloy with a chemical composition (wt.\%) of Nb-14.6, $\mathrm{Zr}-13.3, \mathrm{Fe}-0.02, \mathrm{~N}-0.015, \mathrm{C}-0.03$, Ti-balance. The $\beta$ transus of $\mathrm{Ti}-13 \mathrm{Nb}-13 \mathrm{Zr}$ alloy is about $1015 \mathrm{~K}$. Microstructure of the asreceived specimen is shown in Fig. 1. Before the compression experiments the as-rolled alloy ingot was beta-solution treated at $1073 \mathrm{~K}$ for $30 \mathrm{~min}$ to acquire homogenized microstructure, and then followed by water quenching (WQ). Cylindrical compression samples of $15 \mathrm{~mm}$ height and $10 \mathrm{~mm}$ diameter were prepared with the axis along the rolling direction of the as-received plate according to the ASTM E209 standard. In the following each compression, a computer-controlled, servohydraulic Gleeble-3500 thermo-mechanical simulator was adopted. On this machine two K-type thermocouple wires were welded in the middle of the sample before heating to record the real-time temperature of the specimen, which forms a feedback loop for the dynamic temperature adjustment and controlling under the assist of a thermo-coupled-feedback-controlled AC current loading on the two ends of a cylindrical sample. After that the specimen was fixed at the exact center of the anvils with two graphite foil disks with a diameter of $20 \mathrm{~mm}$ inserted between the specimen ends and anvils as lubricant to reduce friction between the anvils and the sample. In the following, the specimen was resistance heated to the deformation temperature at a heating rate of $10 \mathrm{~K} / \mathrm{s}$, immediately followed by holding at this temperature for $180 \mathrm{~s}$, aiming to obtain a uniform temperature field. This heated specimen was compressed to a true compressive strain of 0.9163 (a height reduction of $60 \%$ ). After completion of each compression, the hot deformed specimen was immediately quenched in water. As above, total twentyfour compressions were repeatedly conducted corresponding to six different temperatures of $923 \mathrm{~K}, 973 \mathrm{~K}, 1023 \mathrm{~K}, 1073 \mathrm{~K}$, $1123 \mathrm{~K}$, and $1173 \mathrm{~K}$, and four different strain rates of $0.01 \mathrm{~s}^{-1}$, $0.1 \mathrm{~s}^{-1}, 1 \mathrm{~s}^{-1}, 10 \mathrm{~s}^{-1}$. Finally, these deformed specimens were sectioned parallel to the compression axis for microstructure observations. After being polished mechanically and etched, the exposed surfaces were observed by optical microscope (OM). The corrosion liquid solution was the Kroll's reagent (5\% HNO3, $10 \% \mathrm{HF}$ and $85 \% \mathrm{H} 2 \mathrm{O}$ ).

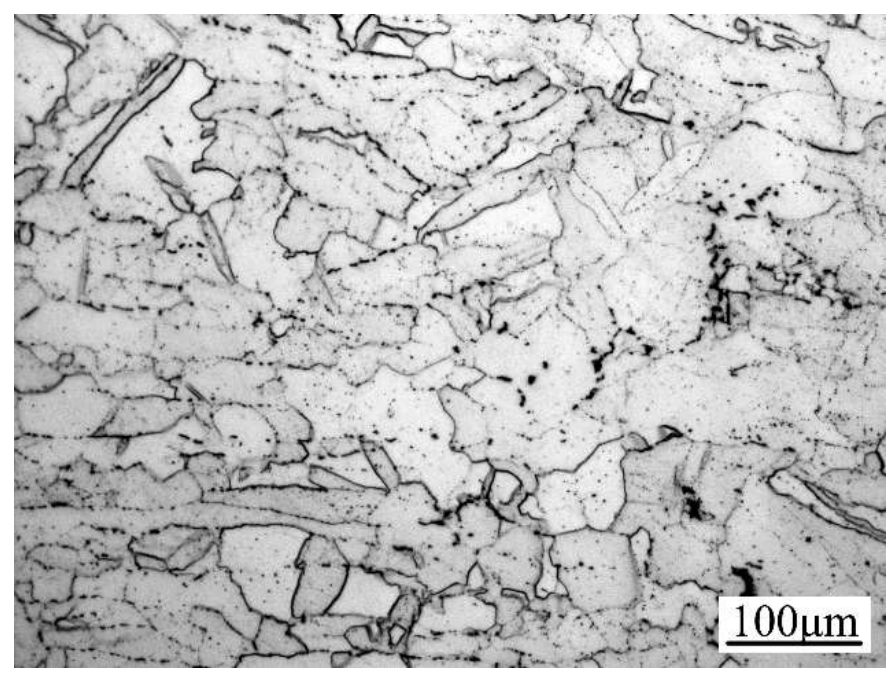

Fig. 1. Microstructure of the as-received specimen

During the compression process, the variations of stress and strain were monitored continuously by a personal computer equipped with an automatic data acquisition system. The true stress and true strain were derived from the measurement of nominal stress-strain relationships according to the following formula: $\sigma_{\mathrm{T}}=\sigma_{\mathrm{N}}\left(1+\varepsilon_{\mathrm{N}}\right), \varepsilon_{\mathrm{T}}=\ln \left(1+\varepsilon_{\mathrm{N}}\right)$, where $\sigma_{\mathrm{T}}$ the true stress, $\sigma_{\mathrm{N}}$ the nominal stress, $\varepsilon_{\mathrm{T}}$ the true strain and $\varepsilon_{\mathrm{N}}$ the nominal strain. 


\section{Descriptions of dynamic softening behaviors}

\subsection{Characteristics of stress-strain curves}

Typical flow stress curves obtained at low and high temperatures, i.e. in two phase $\alpha+\beta$ and single phase $\beta$ regions, are shown in Fig. 2, which shows that both deformation temperature and strain rate have considerable influence on the flow stress. Apparently, the flow stress increases as the response of increasing strain rate and decreasing deformation temperature. From Fig. 2a-d, it can be summarized that flow stress increases in the initial work-hardening regime, reaching a broad peak or stress plateau before dropping in the softening regime. In the two phase region of $\alpha+\beta$, the flow stress increases and reaches a broad peak followed by a steep downfall up to a plateau, followed by a gradual fall toward the steady state stress. This behavior is more obvious at higher strain rates. This flow softening phenomenon may well indicate the occurrence of DRX in traditional qualitative point of view. Otherwise, in the single phase $\beta$ region, the rate of work hardening is almost lower than that in the two phase region and the flow curve degrades more gently leaving a blunt peak, or even no peak, only a flat top. The flat top shapes of true stress-true strain curves show resemblance to that of materials undergoing DRV. The apparent discrepancies between these flow curves obtained at temperatures below and above $\beta$ transus, i.e. in two phase and in single phase regions respectively, reflect the different microstructural evolutions and restoration processes that dominate during individual regime.

\subsection{Elementary mechanisms of dislocation and slipping}

The flow softening mechanism in hot working of two-phase titanium alloys is quite complex. Different softening mechanisms occur due to the two different crystal structures in different temperature ranges. For near $\beta$ Ti-13Nb-13Zr titanium alloy, the $\alpha+\beta$ coexistence results in the complexity of hot deformation behaviors owing to different lattice structures and mechanical properties. The atomic unit cells of the hexagonal close packed (hcp) $\alpha$ titanium and the body-centered cubic (bcc) $\beta$ titanium are schematically shown in Fig. 3 with their most densely packed planes and directions highlighted.

The three most densely packed lattice planes and the lattice parameters of the low temperature $\alpha$ phase are illustrated in Fig. 3a. As for the bcc $\beta$ phase, the unit cell with the most densely packed lattice planes and the lattice parameter is shown Fig. 3b. In hcp crystals (Fig. 3a), the slip systems with the same $\vec{a}$ type Burgers vector of $<11 \overline{2} 0>$ are (0001), $\{10 \overline{1} 0\}$ and $\{10 \overline{1} 1\}$, respectively, which only possesses four independent slip systems. Therefore, the operation of the systems $\{10 \overline{1} 1\}$ with a $\vec{c}+\vec{a}$ type

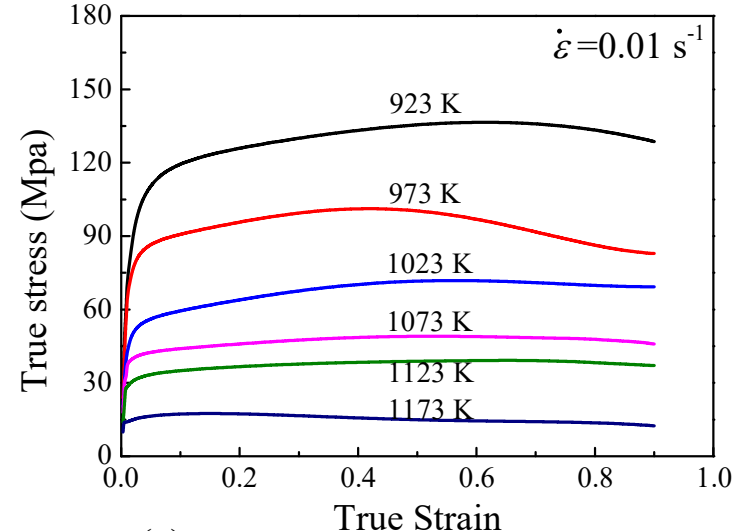

(a)

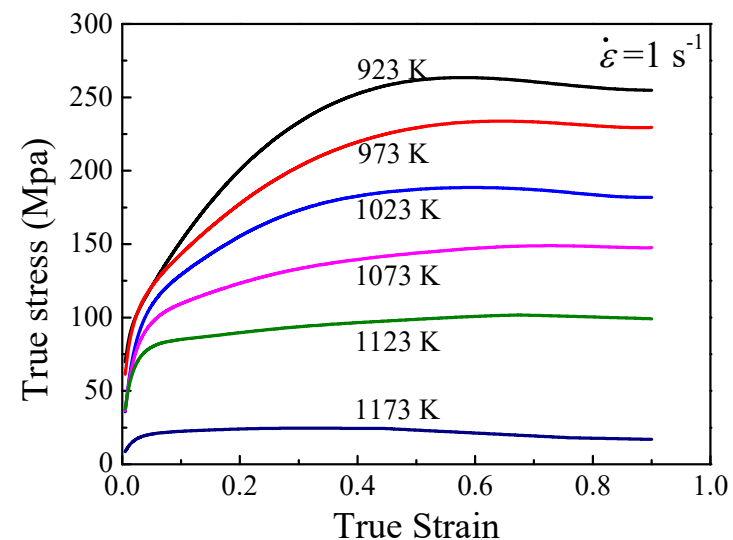

(c)

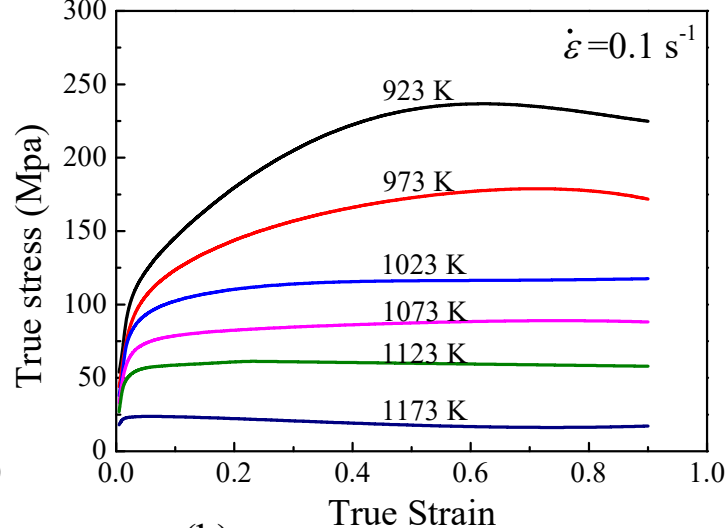

(b)

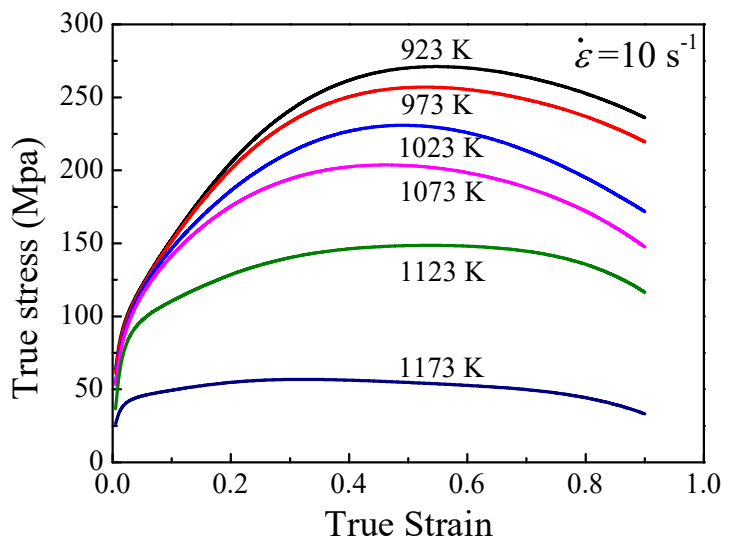

(d)

Fig. 2. True stress-strain curves of Ti-13Nb-13Zr alloy obtained by Gleeble-3500 under different deformation temperatures with strain rates (a) $0.01 \mathrm{~s}^{-1}$, (b) $0.1 \mathrm{~s}^{-1}$, (c) $1 \mathrm{~s}^{-1}$, (d) $10 \mathrm{~s}^{-1}$ 


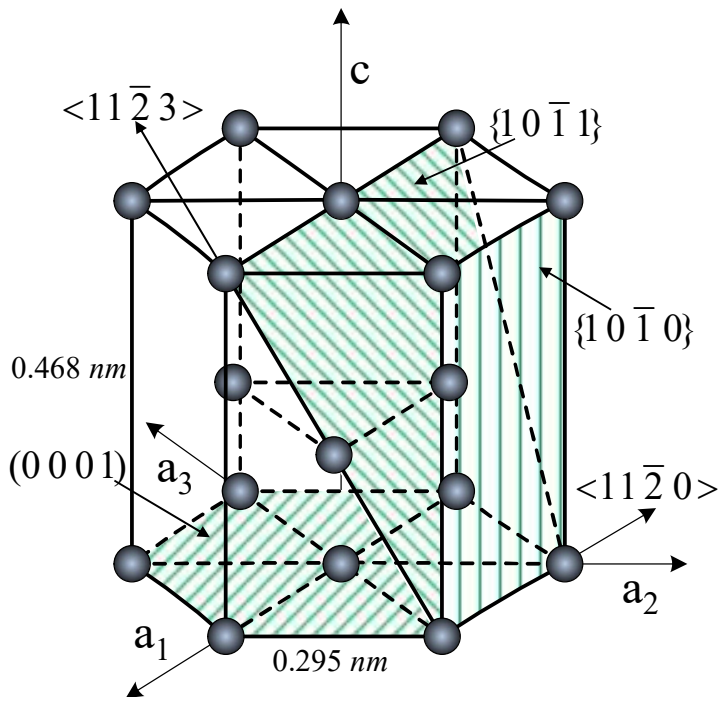

(a)

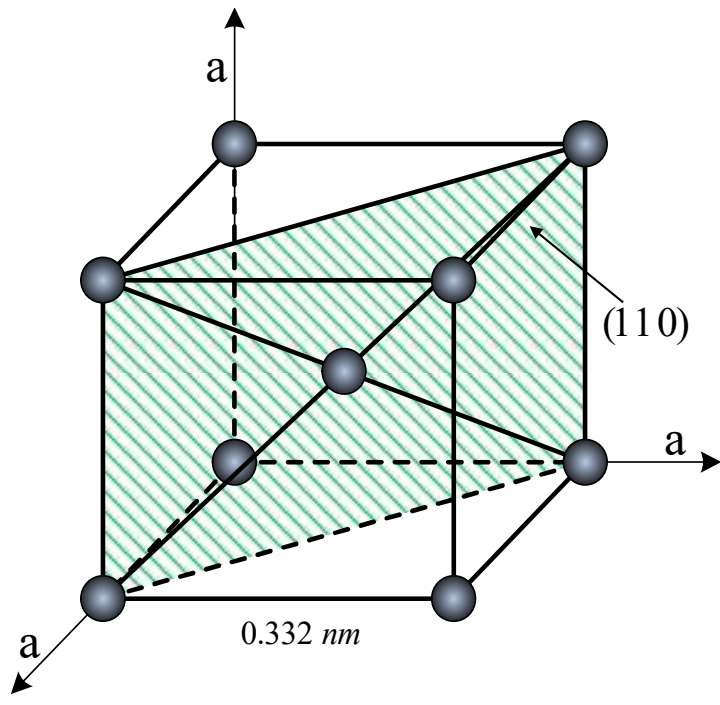

(b)

Fig. 3. Unit cells of $\alpha$ and $\beta$ phase (a) slip planes and slip directions in the hcp $\alpha$ phase, (b) slip planes and slip directions in the bcc $\beta$ phase

Burgers vector of $<11 \overline{2} 3>$ needs to be activated to satisfy von Mises yield criterion which requires at least five independent slip systems for a homogeneous plastic deformation of polycrystal. In the $\beta$ single-phase region with body-centered cubic (bcc) crystal structure at elevated temperature above $\beta$ transus, the basal slip systems are $\{110\},\{112\},\{123\}$, all with the single well-defined Burgers vector of $<111>$.

The stacking fault energy (SFE) variation of different crystal structure types play a significant role in the deformation of metals due to its influence on dislocation mobility and morphology, thus significantly influences its dynamic softening behaviors during hot deformation [20]. For the bcc $\beta$ phase with high SFE, sufficient dislocation rearrangement and elimination annihilates most of the dislocation structures formed in plastic deformation, which leading to the lack of driving force for recrystallization and consequent greater difficulty in onset of DRX [21]. In that context, DRV process is most pronounced restoration process owing to non-conservative mobility and a high cross-slip rate that enables dislocation reordering and hence subgrain formation. If recovery reduces the internal elastic energy to a very large extent, for instance the deformation rate is very low or in cases where the dislocations are very mobile and hence can rearrange very efficiently, recrystallization can be even entirely suppressed. In hcp $\alpha$ phase with low SFE (cross-slip and dynamic and static recovery are inhibited), the dislocation density increases to a high level, and eventually the local dislocation density variation is high enough to permit the nucleation of new grains, followed by the long-range migration of high angle boundaries (HABs). In that context, DRX restoration process will be activated and become the dominant softening mechanism.

So in conclusion, DRV is the dominant softening mechanism before critical condition is satisfied. DRX process will be activated after sufficient structure preparation, and driving force increases as a result of the competition between WH and DRV. In $\alpha+\beta$ two-phase temperature region, the hot deformation behaviors of Ti-13Nb-13Zr titanium alloy present typical DRX softening mechanism. However, in $\beta$-phase temperature region, the hot deformation behaviors in predominant $\beta$-phase present distinct DRV softening mechanism, whereas some discontinuous dynamic recrystallization may occur along $\beta$ grain boundaries [22]. When temperature increases across $\beta$-transus, from a $\alpha+\beta$ two-phase temperature to a $\beta$-phase temperature, the corresponding softening mechanism shift from DRX + DRV to DRV.

\section{Characterization of dynamic softening kinetics}

\subsection{Determination of important material parameters}

As claimed in many pioneering works focusing on the DRV and DRX behaviors [23-25], as for here the investigated Ti-13Nb-13Zr alloy, important material parameters for establishing DRV and DRX kinetic models can be determined by a series of regression analysis on the stress-strain data. In addition, it is valuable to note that such regression analysis are included in the solving process of an Arrhenius type equation (shown as Eq. 1) which has been widely used to describe the interactional relationships of metallic material among the flow stress $(\sigma)$, temperature $(T)$ and strain rate $(\dot{\varepsilon})$ [26]. In this work it is also introduced and adopted.

$$
\dot{\varepsilon}=A F(\sigma) \exp \left(-\frac{Q}{R T}\right)
$$

where $A$ is a constant frequency factor, $F(\sigma)$ is a function of flow stress given by the following Eq. 2 .

$$
F(\sigma)=\left\{\begin{array}{lr}
\sigma^{n^{\prime}} & \alpha \sigma<0.8 \\
\exp (\beta \sigma) & \alpha \sigma>1.2 \\
{[\sinh (\alpha \sigma)]^{n}} & \text { for all } \sigma
\end{array}\right.
$$


where $\sigma$ is true stress (MPa) for a given stain, $A, \alpha, n^{\prime}$ and $n$ are material constants, $\alpha=\beta / n^{\prime}$.

The effects of temperature and strain rate on the deformation behaviors is commonly integrated by a Zener-Hollomon parameter, $Z$, expressed by Eq. 3 representing the temperature compensated strain rate [24]. The hyperbolic law in Arrhenius type equation gives a better approximation between parameter $Z$ and flow stress. Then, flow stress $(\sigma)$, can be written as a function of $Z$ parameter showing in Eq. 4 [27].

$$
Z=\dot{\varepsilon} \exp \left(\frac{Q}{R T}\right)
$$

where $\dot{\varepsilon}$ is strain rate $\left(\mathrm{s}^{-1}\right), R$ gas constant $\left(8.31 \mathrm{~J} \cdot \mathrm{mol}^{-1} \cdot \mathrm{K}^{-1}\right)$, $T$ absolute temperature (K), $Q$ apparent activation energy for deformation $\left(\mathrm{KJ} \cdot \mathrm{mol}^{-1}\right)$.

$$
\sigma=\frac{1}{\alpha} \ln \left\{\left(\frac{Z}{A}\right)^{1 / n}+\left[\left(\frac{Z}{A}\right)^{2 / n}+1\right]^{1 / 2}\right\}
$$

where $A$ is a constant frequency factor, $Z$ is Zener-Hollomon parameter given by the previous Eq. 1

The constants of the hyperbolic sine equation can be determined by substituting each $F(\sigma)$ of Eq. 2 into Eq. 1 and taking natural logarithms on both sides. The mathematical expressions are shown in the following Eqs. 5-7.

$$
\begin{gathered}
\ln \dot{\varepsilon}+\frac{Q}{R T}=\ln A+n^{\prime} \ln \sigma \\
\ln \dot{\varepsilon}+\frac{Q}{R T}=\ln A+\beta \sigma \\
\ln \dot{\varepsilon}+\frac{Q}{R T}=\ln A+n \ln [\sinh (\alpha \sigma)]
\end{gathered}
$$

Eq. 5 and Eq. 6 indicate obvious linear relationships between $\ln \dot{\varepsilon}$ and $\ln \sigma$, and $\ln \dot{\varepsilon}$ and $\sigma$. The values of $n^{\prime}$ and $\beta$ can be calculated from the slopes of the linear fitted lines in $\ln \dot{\varepsilon}-\ln \sigma$ and $\ln \dot{\varepsilon}-\sigma$ plots, respectively. Here the mean values of the material constants are shown in the following: $n^{\prime}=6.04213$, $\beta=0.065015, \alpha=\beta / n^{\prime}=0.0108$.

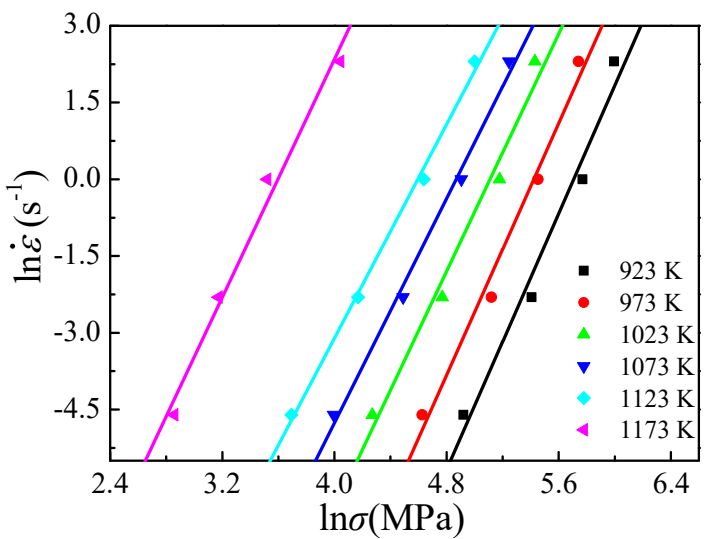

(a)

Fig. 4. The relationships between (a) $\ln \dot{\varepsilon}$ versus $\ln \sigma$, (b) $\ln \dot{\varepsilon}$ versus $\sigma$
Differentiating Eq. 7 with respect to $1 / T$ and $\ln [\sinh (\alpha \sigma)]$ respectively ends to:

$$
\begin{gathered}
n=\left.\frac{\partial \ln \dot{\varepsilon}}{\partial \ln [\sinh (\alpha \sigma)]}\right|_{T} \\
Q=\left.R n \frac{\partial \ln [\sinh (\alpha \sigma)]}{\partial(1 / T)}\right|_{\dot{\varepsilon}}
\end{gathered}
$$

Therefore, the linear relationships of $\ln \dot{\varepsilon}-\ln [\sinh (\alpha \sigma)]$ and $\ln [\sinh (\alpha \sigma)]-1 / T$ were obtained as shown in Fig. 5a-b. The mean value of all the slopes of $\ln \dot{\varepsilon}-\ln [\sinh (\alpha \sigma)]$ (Fig. 5a) was accepted as $n$ value, and here it was calculated as 4.303. The values of $Q$ were determined from the slopes of $\ln [\sinh (\alpha \sigma)]$ vs. $1 / T$ (Fig. 5b) through averaging the values under different strain rates.

Substituting $\alpha, n, Q$ and four sets of $\dot{\varepsilon}, T$ and the peak stress data from compression tests into Eq. 7, the mean value of material constant $A$ was obtained as $2.881 \times 10^{17} \mathrm{~s}^{-1}$.

Thus, the relationships between $\dot{\varepsilon}, T$ and $\sigma$ of Ti-13Nb-13Zr alloy were expressed as Eq. 10.

$$
\dot{\varepsilon}=2.3431 \times 10^{19}[\sinh (0.0108 \sigma)]^{4.303} \exp \left(-\frac{4.064418 \times 10^{5}}{R T}\right)
$$

Substituting the material constants $A, a, n$ and $Z$ into Eq. 5, the expression of peak stress $\left(\sigma_{\mathrm{p}}\right)$, can be given by:

$$
\sigma_{\mathrm{p}}=92.5926 \ln \left\{\begin{array}{l}
\left(\frac{Z}{2.3431 \times 10^{19}}\right)^{1 / 4.303}+ \\
+\left[\left(\frac{Z}{2.3431 \times 10^{19}}\right)^{2 / 4.303}+1\right]^{1 / 2}
\end{array}\right\}
$$

The peak strain $\left(\varepsilon_{\mathrm{p}}\right)$ is proposed as follows:

$$
\varepsilon_{\mathrm{p}}=a_{1} Z^{m_{1}}
$$

where $\mathrm{Z}$ is Zener-Hollomon parameter expressed by Eq. 3, $a_{1}$ and $m_{1}$ are material constants.

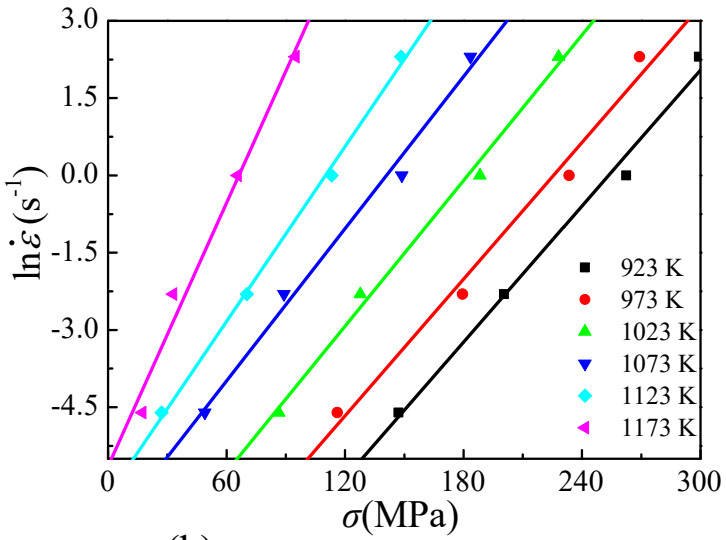

(b) 


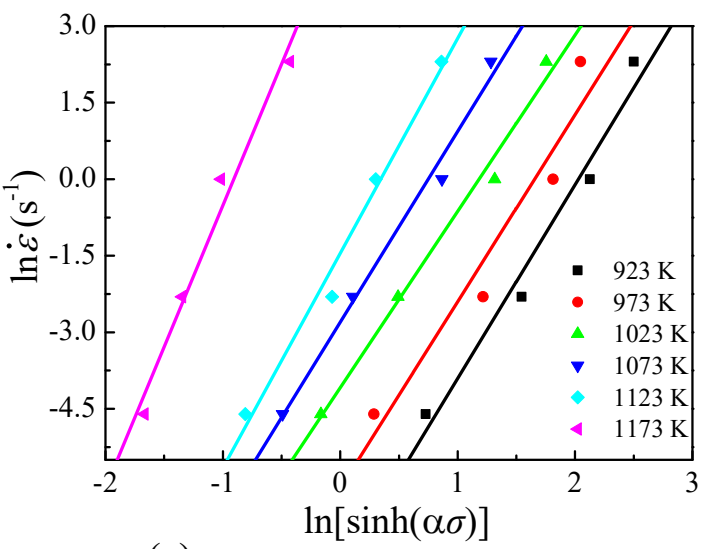

(a)

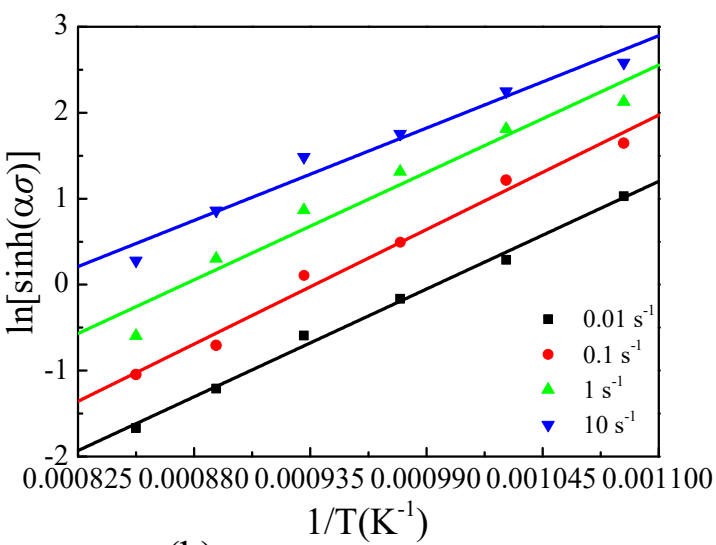

(b)

Fig. 5. The relationships between (a) $\ln \dot{\varepsilon}$ versus $\ln [\sinh (\alpha \sigma)]$, and (b) $\ln [\sinh (\alpha \sigma)]$ vs. $1 / T$

Substituting Eq. 3 into Eq. 12 and then taking natural logarithm on both sides, the expression can be shown as follows:

$$
\ln \varepsilon_{\mathrm{p}}=\ln a_{1}+m_{1} \ln \dot{\varepsilon}+m_{1} \frac{Q}{R T}
$$

As for the value of $m_{1}$ at a constant deformation temperature, it is easy to acquire from the average value of the slopes shown in Fig. 6. Then, substituting $m_{1}, Q$ and a set of $\dot{\varepsilon}, T$ into Eq. 12 , the mean value of material constant $a_{1}$ was obtained as 0.12051 . Accordingly: $\varepsilon_{\mathrm{p}}=0.12051 Z^{0.03381}$.

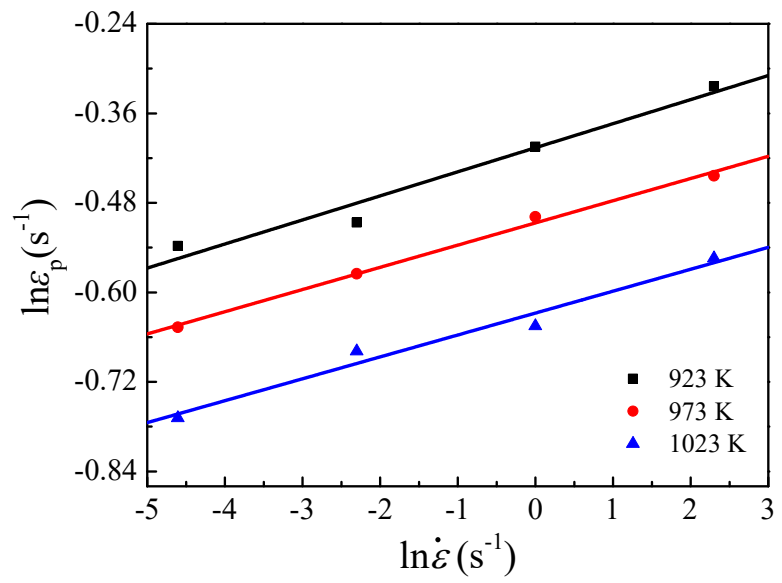

Fig. 6. The relationship between $\ln \varepsilon_{\mathrm{p}}$ and $\ln \dot{\varepsilon}$

\subsection{Kinetic model for DRV dynamic softening}

As mentioned above, at the temperature above $1073 \mathrm{~K}$ (above $\beta$-transus) and the strain rate of $0.01-1 \mathrm{~s}^{-1}$, DRV process acts as the predominant softening mechanism. Without obvious softening effect by DRX, dislocations can only interact with each other to decrease the distortion by the combination with the same sign and the annihilation with different signs through cross-slipping and climbing [28]. Consequently, the flow stress tends to increase until the saturated stress $\left(\sigma_{\mathrm{sat}}\right)$ has been reached in the initial work-hardening regime, which indicates that the competition between working-hardening and dynamic softening predominated by DRV achieves the balance [29]. The saturated stress $\left(\sigma_{\text {sat }}\right)$ is defined as the maximum hardening effect during the deformation process with only DRV softening mechanism, which can be attained through the work-hardening rate $(\theta)$ by the following Eq. 14:

$$
\theta_{\mathrm{DRV}}=\frac{\partial \sigma_{\mathrm{DRV}}}{\partial \varepsilon}=0
$$

Recognition the occurrence and the extent of DRV based on experimental observation is a time and cost consumable work, and sometimes it needs difficult procedures. The experimental method may not be reasonable, especially when the researchers require a rapid way to find the evolution of DRV extent. Determining the kinetics of DRV by using stress-strain curves is relatively complex in comparison with that of DRX mainly because of fewer characteristic points existing on the stress-strain curves with DRV softening.

Kocks and Mecking [16] proposed a model (K-M model) to describe the dislocation evolution under the competition between work-hardening and DRV softening by considering a homogeneous dislocation distribution, and it has been widely employed to characterize its density variation as:

$$
\frac{d \rho_{\mathrm{DRV}}}{d \varepsilon}=h-r \rho
$$

where $h$ is the rate of work hardening and $r$ specifies the rate of dynamic softening induced by DRV at a specific strain rate and temperature.

Considering that $h$ and $r$ are strain independent, integration of Eq. 15 leads to:

$$
\rho=\frac{h}{r}-\frac{c_{1}}{r} \exp (-r \varepsilon)
$$

The constant value of $c_{1}$ can be calculated by substituting the initial dislocation density $\rho_{0}$ before plastic deformation into Eq. 16. Accordingly:

$$
\rho=\rho_{0} \exp (-r \varepsilon)+\frac{h}{r}(1-\exp (-r \varepsilon))
$$


The widely used Taylor relation was utilized to characterize the response of flow stress to dislocation density as [14]:

$$
\sigma=\alpha G M b \sqrt{\rho}
$$

where $\alpha$ is Taylor constant, $\sim 0.5, M$ represents Taylor conversion factor from shear to normal strain, 3.06 [30]. $G$ is the shear modulus and $b$ is the magnitude of Burgers vector.

As the strain reaches larger values $(\varepsilon \rightarrow \infty)$, flow stress for DRV curves reaches a relative constant value of $\sigma_{\text {sat }}$. By considering Eqs. 17 and 18:

$$
\sigma_{\text {sat }}=\alpha G M b \sqrt{\frac{h}{r}}
$$

The flow stress model of DRV can be described by [24]:

$$
\sigma_{\mathrm{DRV}}=\left[\sigma_{\text {sat }}^{2}-\left(\sigma_{\text {sat }}^{2}-\sigma_{0}^{2}\right) \exp (-r \varepsilon)\right]^{1 / 2}
$$

where $\sigma_{\text {sat }}$ and $\sigma_{0}$ are the saturated and initial yield stresses, respectively. The flow stress data before the critical strain of DRX are chosen to determine the coefficients of Eq. 20. As no obvious yield points on the high temperature stress-strain curves, flow stresses with plastic deformation up to $0.2 \%$ were taken as the initial yield stresses [31-33]. that:

By differentiating Eq. 20 with respect to $\varepsilon$, it can be shown

$$
\begin{aligned}
\frac{d \sigma}{d \varepsilon}= & 0.5\left[\sigma_{\text {sat }}^{2}-\left(\sigma_{\text {sat }}^{2}-\sigma_{0}^{2}\right) \exp (-r \varepsilon)\right]^{-1 / 2} \times \\
& \times r\left(\sigma_{\text {sat }}^{2}-\sigma_{0}^{2}\right) \exp (-r \varepsilon)
\end{aligned}
$$

Multiplying $d \sigma / d \varepsilon$ by $\sigma$, leads to the following relation:

$$
\sigma \frac{\mathrm{d} \sigma}{\mathrm{d} \varepsilon}=0.5 r\left(\sigma_{\mathrm{sat}}^{2}-\sigma^{2}\right)
$$

Noted that there is a linear relation of $\sigma \theta-\sigma^{2}$.Thus the value of the recovery parameter $r$ is obtained from regression analysis and that of $\sigma_{\text {sat }}$ from the intercept.
Rearrangement of Eq. 20 gives:

$$
\frac{\sigma^{2}-\sigma_{0}^{2}}{\sigma_{\text {sat }}^{2}-\sigma_{0}^{2}}=1-\exp (-r \varepsilon)
$$

Strain rate $\dot{\varepsilon}$ is introduced into Eq. 23 in order to involve the effect of time $(t)$ by:

$$
\dot{\varepsilon}=\left(\varepsilon-\varepsilon_{\text {start }}\right) / t
$$

where $\varepsilon_{\text {start }}$ is the strain at which the related phenomenon is initiated. For DRV, the process starts immediately after straining [31]. So for DRV:

$$
\varepsilon_{\text {start }}=0 \rightarrow \varepsilon=\dot{\varepsilon} t
$$

Thus, Eq. 23 is rewritten into the following form:

$$
\frac{\sigma^{2}-\sigma_{0}^{2}}{\sigma_{\text {sat }}^{2}-\sigma_{0}^{2}}=1-\exp (-r \dot{\varepsilon} t)
$$

The left-hand side of Eq. 26 represents the ratio of the stress increment at any time during deformation and the total stress variation in the process of DRV. It consists of parameters that can be attained from stress-strain curves for the DRV condition. Eq. 27 can be considered as the fraction of dynamic recovery when the softening mechanisms is dominated by DRV [14].

$$
X_{\mathrm{DRV}}=1-\exp \left(-r \dot{\varepsilon} t^{n}\right)
$$

where the Avrami parameters can be considered as $k=r \dot{\varepsilon}$ and time exponent $n=1$.

The DRV kinetic model is summarized in Table 1. Fig. 7 shows the time-dependent DRV fraction curves under different conditions. As it is expected, the fraction of DRV increases with increasing the strain or consequently, with the time. The increasing rate of $X_{\mathrm{DRV}}$ decreases with increasing of time. The reason is reducing of the stored energy caused by the dominance of work hardening versus work softening at the early stage of deformation. The values of $X_{\mathrm{DRV}}$ reach unity after a specific time, which means the DRV is at a stable dynamic condition. It should be noted that the higher the strain rate and the deforming temperature are, the faster the process of DRV.

DRV kinetic model of Ti-13Nb-13Zr

\begin{tabular}{|c|c|}
\hline \hline Quantity & $\sigma_{\mathrm{DRV}}=\left[\sigma_{\text {sat }}^{2}-\left(\sigma_{\text {sat }}^{2}-\sigma_{0}^{2}\right) \exp (-r \varepsilon)\right]^{1 / 2}$ \\
\hline DRV flow stress & $\sigma_{\text {sat }}=52.0833 \ln \left\{\left(\frac{Z}{2.3035 \times 10^{26}}\right)^{1 / 3.4313}+\left[\left(\frac{Z}{2.3035 \times 10^{26}}\right)^{2 / 3.4313}+1\right]^{1 / 2}\right\}$ \\
\hline Saturated stress & $\sigma_{0}=-204.6309-6.61358 \ln Z$ \\
\hline Initial yield stress & $r=14210.8353 Z^{-0.13887}$ \\
\hline DRV soften coefficient & $X_{\mathrm{DRV}}=1-\exp (-r \varepsilon)=1-\exp (-r \dot{\varepsilon} t)$ \\
\hline DRV fraction &
\end{tabular}




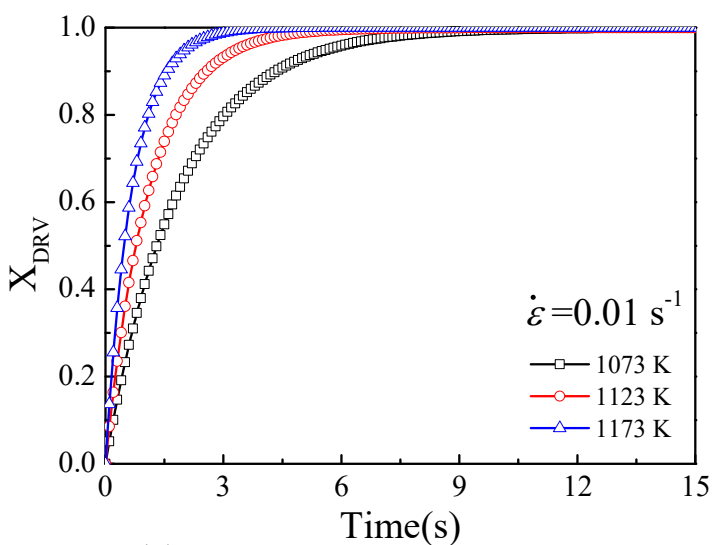

(a)

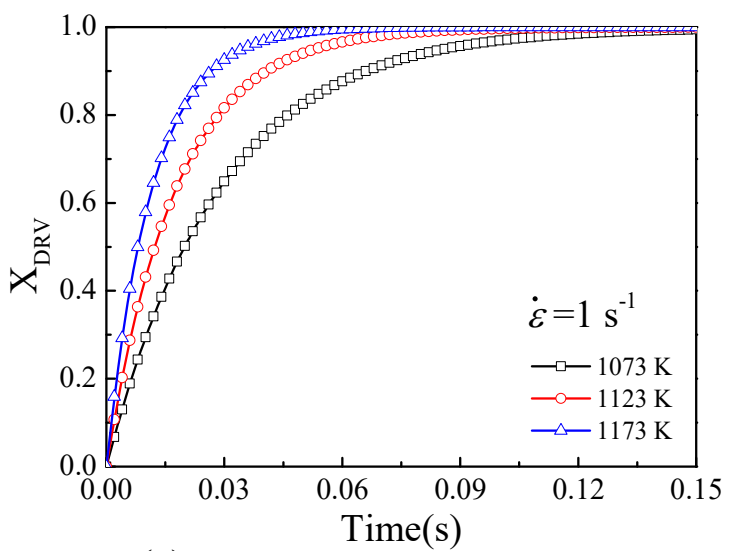

(c)

Fig. 7. Variations of $X_{D R V}$ with time for the strain rates of (a) $0.01 \mathrm{~s}^{-1}$,

\subsection{Kinetic model for DRX dynamic softening}

Dynamic softening represents a convolution of DRV and DRX contributions. A variety of data-manipulation techniques have been proposed to separate the contribution of DRX, usually through a subtraction of a portion of the stress which is attributed by DRV [34-36]. The work describes specifically the mathematical method for separating the contribution of DRX on the basis of previous studies.

The critical strain $\left(\varepsilon_{\mathrm{c}}\right)$ of material is the prerequisite for the research on DRX, which indicating the critical condition of predominant dynamic softening mechanism changing from DRV to DRX. In previous studies, work-hardening rate $(\theta=d \sigma / d \varepsilon)$ has been widely employed to investigate the microstructural transformation during hot deformation. Fig. 8 shows a schematic plot of the work hardening rate $(\theta=d \sigma / d \varepsilon)$ versus stress $(\sigma)$ [37].

McQueen et al. [23] suggested that the deviation point of the linear relationship between $\theta$ and $\sigma$ should be defined as the critical strain position. Poliak and Jonas [38] developed a more precise method to identify the critical strain by the minimum value of $-\partial \theta / \partial \sigma$.

In this research, Poliak-Jonas criterion has been utilized to identify the onset of DRX by the presence of inflections in $\theta-\sigma$ and minimums in $-\partial \theta / \partial \sigma$ curves[39]. The values of critical strain are determined through $\theta-\sigma$ curves as shown in Fig. 9a-d. The

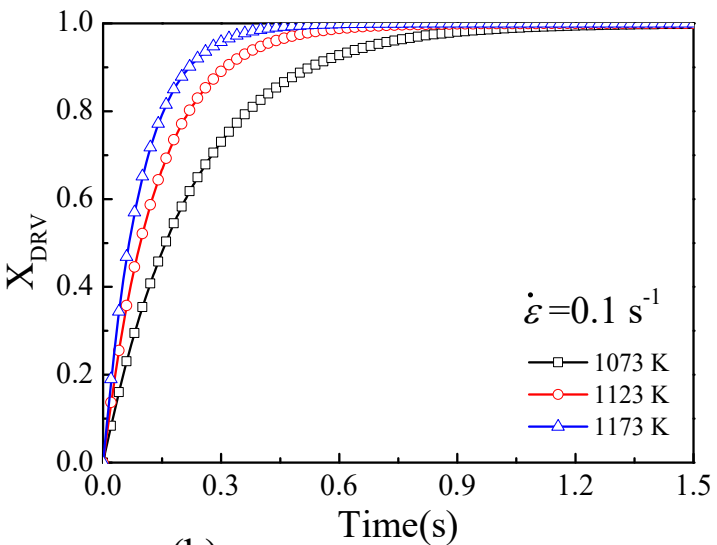

(b)

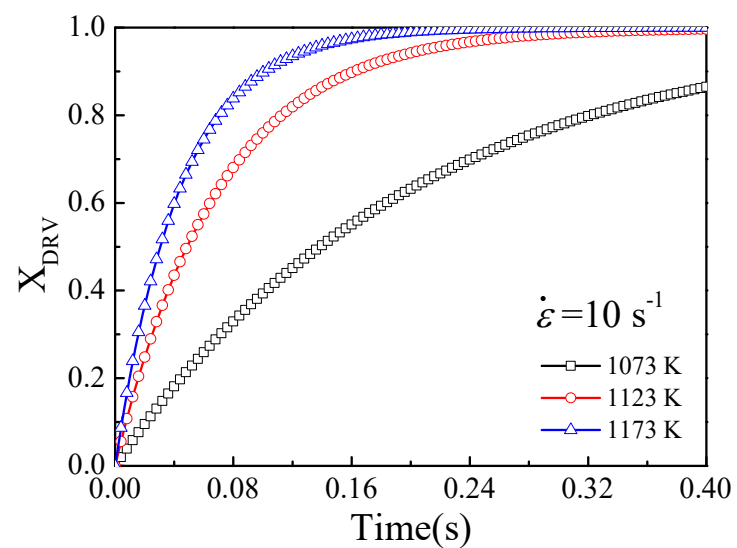

(d)

(b) $0.1 \mathrm{~s}^{-1}$, (c) $1 \mathrm{~s}^{-1}$, (d) $10 \mathrm{~s}^{-1}$

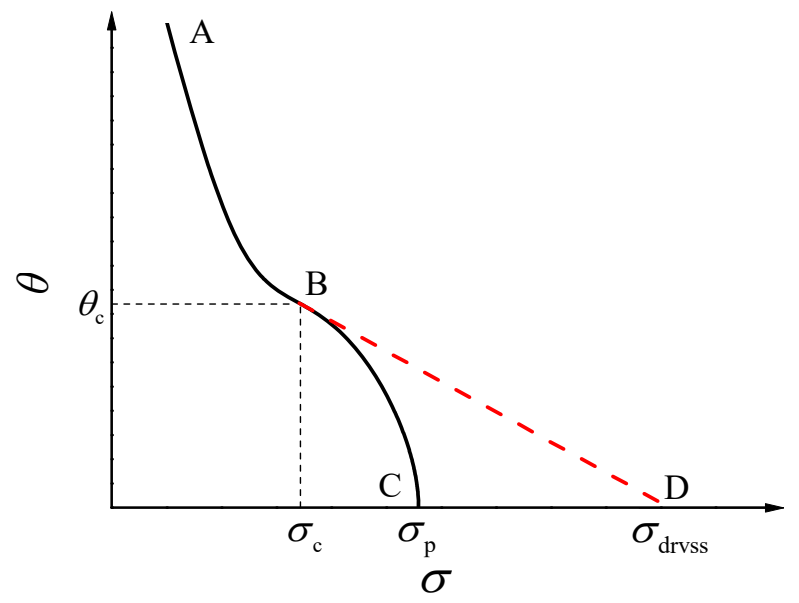

Fig. 8. Schematic presentation of the strain hardening versus stress graph for dynamically recovered (ABD) and dynamically recrystallized $(\mathrm{ABC})$ material.

influence of strain rate and temperature on the critical strain can be convert into Sellars model as following [14]:

$$
\varepsilon_{\mathrm{c}}=k \varepsilon_{\mathrm{p}}
$$

where $\varepsilon_{\mathrm{p}}$ is the peak strain determined by Eq. 12. It is easy to obtain the values of $k$ at constant deformation temperature from the slopes shown in Fig. 10. Consequently, $\varepsilon_{\mathrm{c}}=0.4804 \varepsilon_{\mathrm{p}}$. 


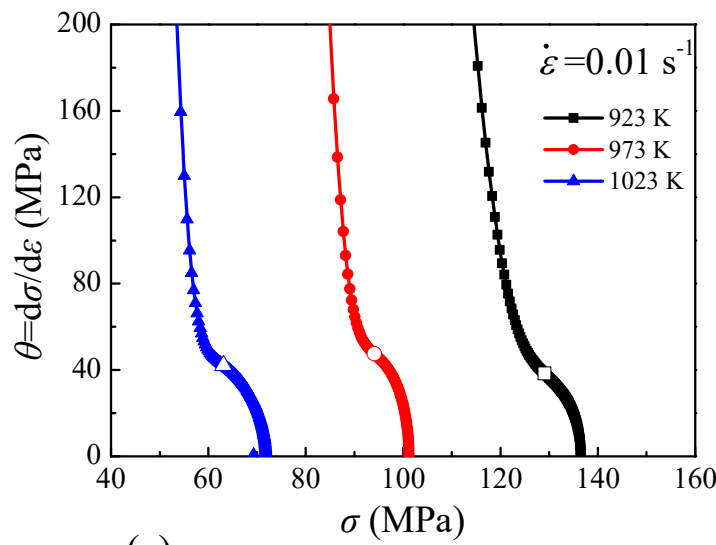

(a)

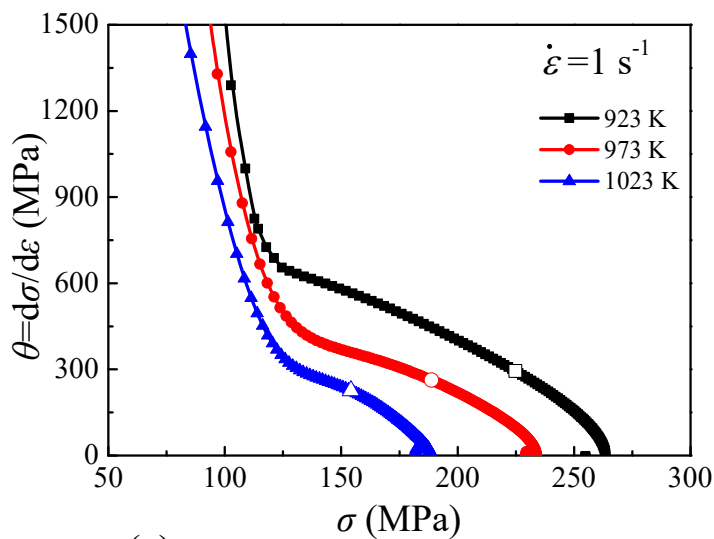

(c)

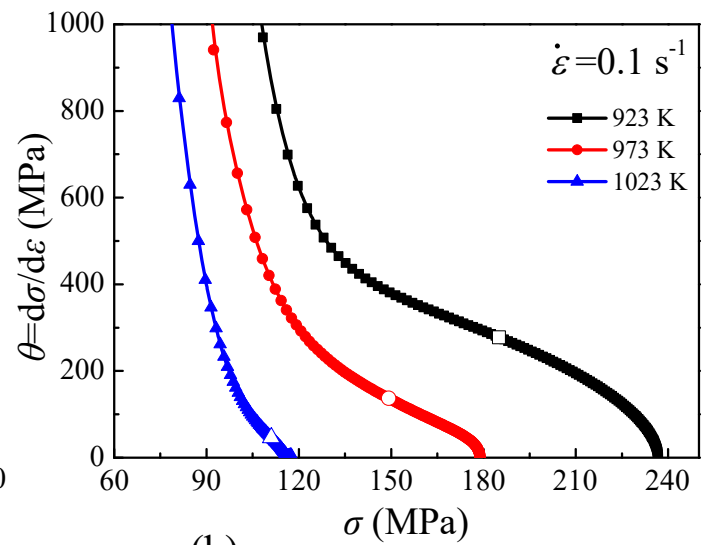

(b)

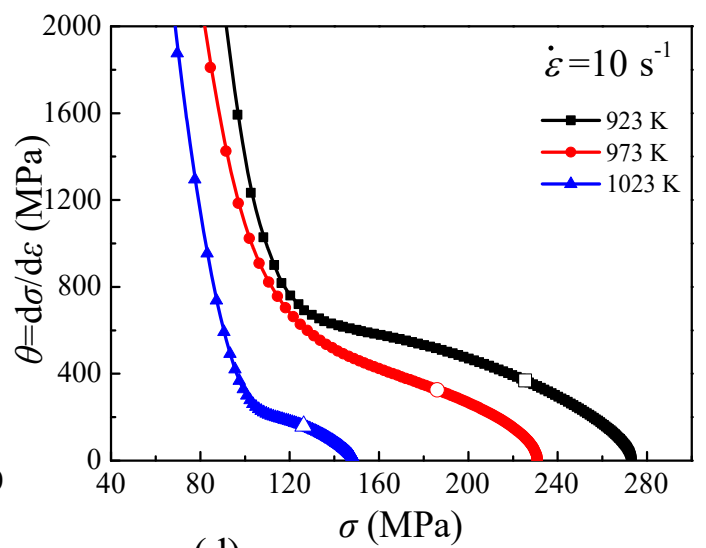

(d)

Fig. 9. $d \sigma / d \varepsilon$ versus $\sigma$ plots up to the peak points of the true stress-strain curves under different deformation temperatures with strain rates (a) $0.01 \mathrm{~s}^{-1}$, (b) $0.1 \mathrm{~s}^{-1}$, (c) $1 \mathrm{~s}^{-1}$, (d) $10 \mathrm{~s}^{-1}$

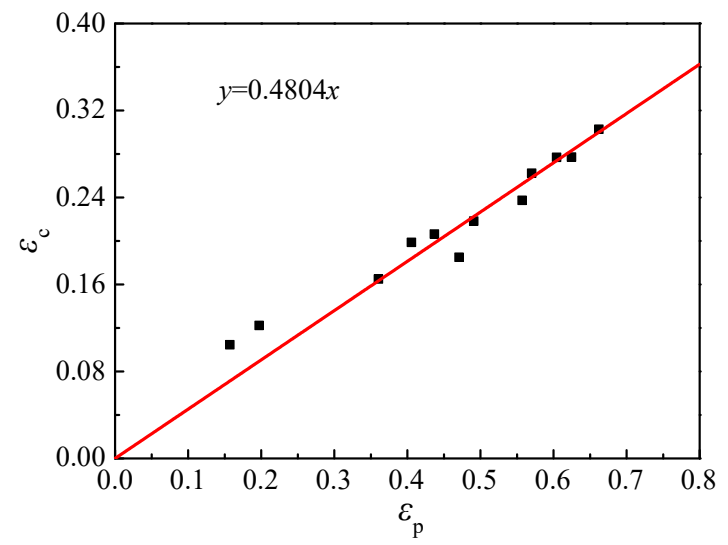

Fig. 10. The relationship between $\varepsilon_{\mathrm{c}}$ and $\varepsilon_{\mathrm{p}}$

Generally, the recrystallized volume fraction $X_{\mathrm{DRX}}$ can be expressed by a function of true strain, in the form of a modified Avrami equation $[40,41]$ :

$$
X_{\mathrm{DRX}}=1-\exp \left[-\beta_{\mathrm{d}}\left(\frac{\varepsilon-\varepsilon_{\mathrm{c}}}{\varepsilon_{\mathrm{p}}}\right)^{k_{\mathrm{d}}}\right]
$$

where $X_{\mathrm{DRX}}$ is the volume fraction of DRX grains. $\varepsilon$ is the true strain. $\beta_{\mathrm{d}}$ and $k_{\mathrm{d}}$ are the Avrami material constants.

In order to determine the $\beta_{\mathrm{d}}$ and $k_{\mathrm{d}}$ in Eq. $29, X_{\mathrm{DRX}}$ should be determined firstly. Eq. exhibits a convenient way to determine
$X_{\mathrm{DRX}}$ only from a set of true stress-strain curves [37]. By this way the $X_{\mathrm{DRX}}$ corresponding to any strain, strain rate and temperature can be calculated easily.

$$
X_{\mathrm{DRX}}=\frac{\sigma_{\mathrm{drvx}}^{2}-\sigma_{\mathrm{drxx}}^{2}}{\sigma_{\mathrm{drvss}}^{2}-\sigma_{\mathrm{drxss}}^{2}}
$$

where $\sigma_{\mathrm{drvx}}$ is the theoretical calculated transient state stress at a transient strain $\left(\varepsilon_{x}\right)$ on an ideal DRV softening stress-strain curve achieved by a mathematical fitting method (Schematic presented in Fig. 8 and Fig. 11), and $\sigma_{\text {drvss }}$ is its steady state stress. $\sigma_{\mathrm{drxx}}$ is the transient state stress at $\operatorname{strain}\left(\varepsilon_{x}\right)$ on an actual

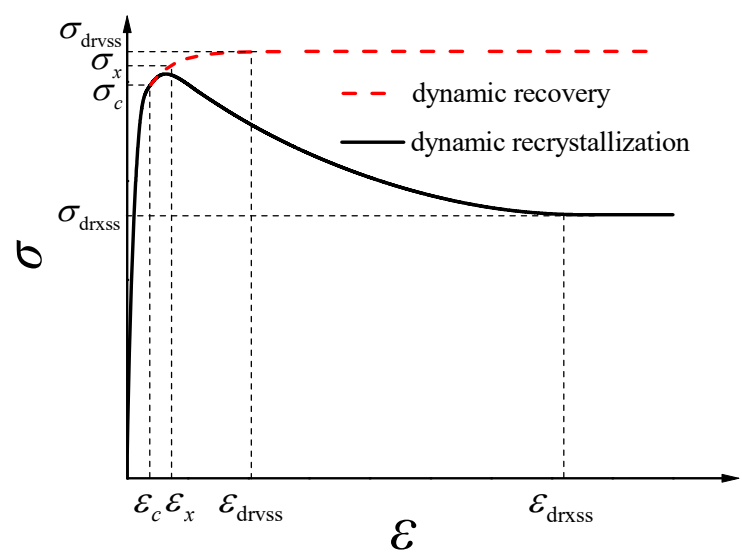

Fig. 11. Schematic presentation of the flow curves for DRV and DRX 
stress-strain curve with both DRV and DRX softening, while DRX predominant, and $\sigma_{\text {drxss }}$ is its steady state stress.

Combined Eq. 29 with Eq. 30, the flow stress model of DRX can be expressed as follows:

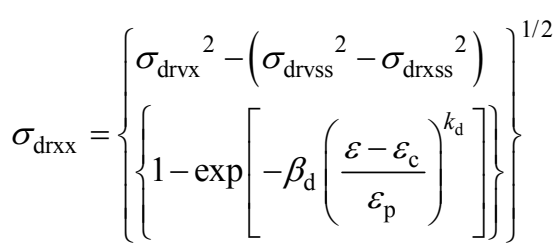

Eq. 29 can be rewritten in double natural logarithm form as follows:

$$
\ln \ln \left(\frac{1}{1-X_{\mathrm{DRX}}}\right)=\ln \beta_{\mathrm{d}}+k_{\mathrm{d}} \ln \left(\frac{\varepsilon-\varepsilon_{\mathrm{c}}}{\varepsilon_{\mathrm{p}}}\right)
$$

From Eq. 32, it can be seen that he values of $k_{\mathrm{d}}$ and $\beta_{\mathrm{d}}$ can be determined by linear fitting (as Fig. 12) of the relationships between $\ln \left[-\ln \left(1-X_{\mathrm{DRX}}\right)\right]$ and $\ln \left[\left(\varepsilon-\varepsilon_{\mathrm{c}}\right) / \varepsilon_{\mathrm{p}}\right]$ under various strains, strain rates and temperatures, since each stress-strain curve corresponds to a set of $\varepsilon_{\mathrm{c}} \varepsilon_{\mathrm{p}}$ and $X_{\mathrm{DRX}}$ at certain $\varepsilon$. The average values of $k_{\mathrm{d}}$ and $\beta_{\mathrm{d}}$ were calculated as 0.5994 and 0.9339 respectively.

The DRX kinetic model solved in this work is listed in Table 2, by which the dynamic responses of DRX volume

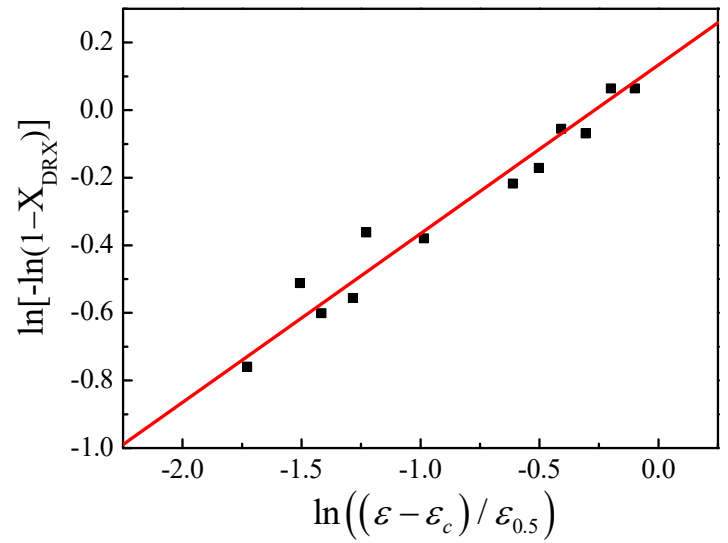

Fig. 12. The relationships between $\ln \left[-\ln \left(1-X_{\mathrm{DRX}}\right)\right]$ and $\ln \left[\left(\varepsilon-\varepsilon_{\mathrm{c}}\right) / \varepsilon_{\mathrm{p}}\right]$

fraction to the strain, temperature and strain rate are illustrated in Fig. 13a-d. Apparently, the DRX volume fractions increase with increasing strain, and overall present as normal S-curves. Comparing these curves with one another, it is found that the DRX volume fraction is higher at a higher temperature or at a lower strain rate under a certain strain. Recrystallization kinetics accelerates with decreasing strain rate, as well as increasing deformation temperature. The deformation strain required for the same amount of DRX volume fraction increases with decreas-

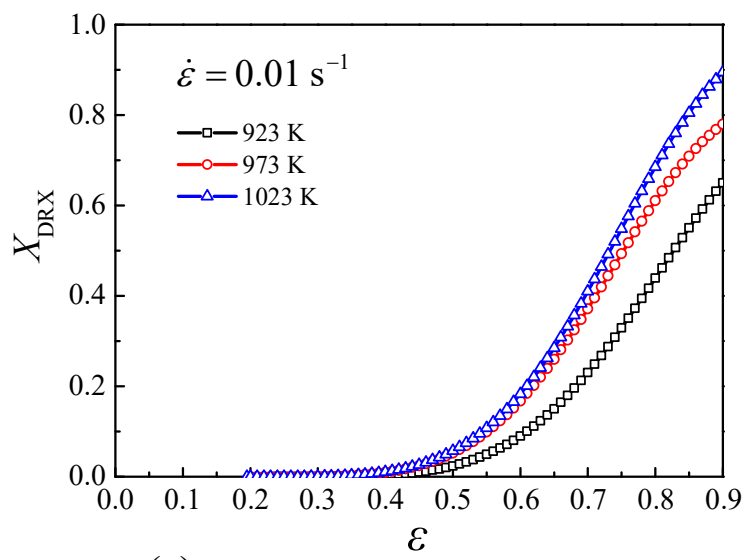

(a)

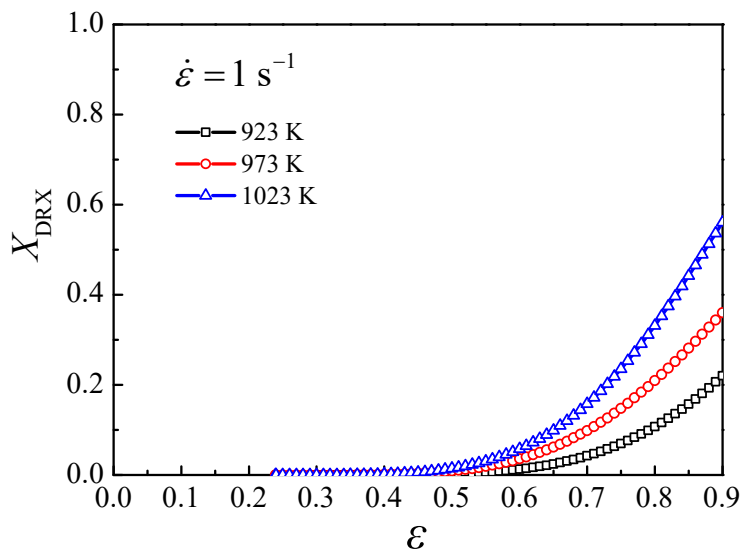

(c)

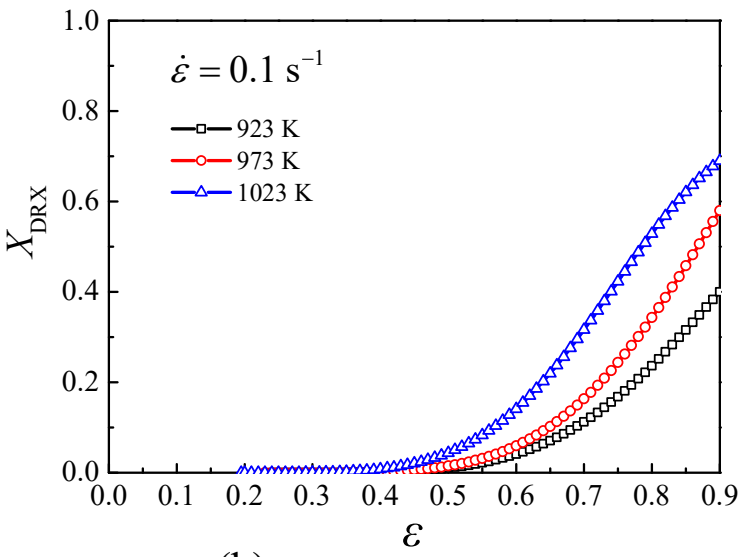

(b)

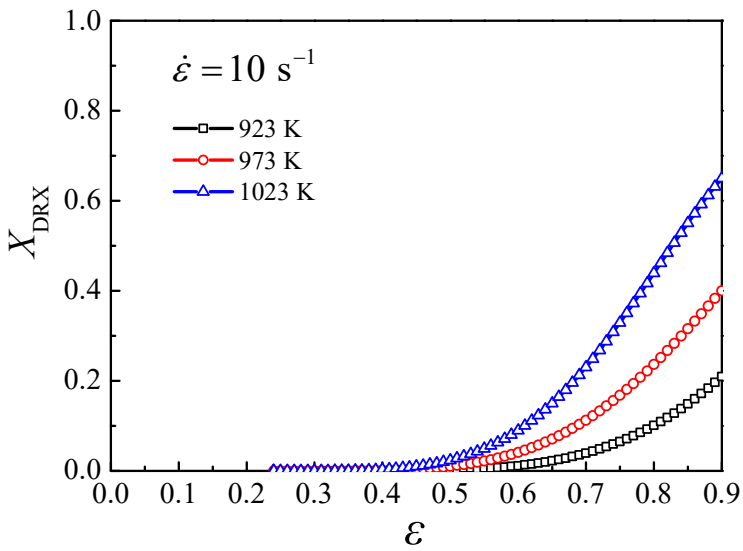

(d)

Fig. 13. Predicted volume fractions of dynamic recrystallization obtained under different deformation temperatures with strain rates (a) $0.01 \mathrm{~s}^{-1}$, (b) $0.1 \mathrm{~s}^{-1}$, (c) $1 \mathrm{~s}^{-1}$, (d) $10 \mathrm{~s}^{-1}$ 
DRX kinetic model of Ti-13Nb-13Zr

\begin{tabular}{|c|c|}
\hline \hline Quantity & Equation \\
\hline DRX flow stress & $\sigma_{\text {drxx }}=\left\{\sigma_{\text {drrx }}{ }^{2}-\left(\sigma_{\text {drrss }}{ }^{2}-\sigma_{\text {drxss }}{ }^{2}\right)\left\{1-\exp \left[-0.5994\left(\frac{\varepsilon-\varepsilon_{\mathrm{c}}}{\varepsilon_{\mathrm{p}}}\right)^{0.9339}\right]\right\}\right\}^{1 / 2}$ \\
\hline Theoretical DRV Steady state stress & $\sigma_{\text {drrss }}=149.2537 \ln \left\{\left(\frac{Z}{1.0089 \times 10^{24}}\right)^{1 / 4.4196}+\left[\left(\frac{Z}{1.0089 \times 10^{24}}\right)^{1 / 4.4196}+1\right]^{1 / 2}\right\}$ \\
\hline Steady state stress & $\sigma_{\text {drrss }}=149.2537 \ln \left\{\left(\frac{Z}{9.9153 \times 10^{19}}\right)^{1 / 6.4967}+\left[\left(\frac{Z}{9.9153 \times 10^{19}}\right)^{1 / 6.4967}+1\right]^{1 / 2}\right\}$ \\
\hline Peak stress & $\sigma_{\mathrm{p}}=92.5926 \ln \left\{\left(\frac{Z}{2.3431 \times 10^{19}}\right)^{1 / 4.303}+\left[\left(\frac{Z}{2.3431 \times 10^{19}}\right)^{2 / 4.303}+1\right]^{1 / 2}\right\}$ \\
\hline DRX fraction & $X_{\text {DRX }}=1-\exp \left[-0.5994\left(\frac{\varepsilon-\varepsilon_{\mathrm{c}}}{\varepsilon_{\mathrm{p}}}\right)^{0.9339}\right]$ \\
\hline Critical strain & $\varepsilon_{\mathrm{c}}=0.4804 \varepsilon_{\mathrm{p}}$ \\
\hline Peak strain & $\varepsilon_{\mathrm{p}}=0.12051 Z^{0.03381}$ \\
\hline
\end{tabular}

ing deformation temperature or increasing strain rate. It should be noted that complete recrystallization $\left(X_{\mathrm{DRX}}=1\right)$ cannot be acquired for all deformation conditions.

\section{Microstructure evolution during hot deformation}

Dynamic softening behaviors could be directly reflected and identified from the microstructural evolutions during hot deformations. The presence of equiaxed or spheroidized grains from the frozen microstructures obtained by a hot compression has been considered as the significant sign for DRX [23]. The microstructures with wavy $\beta$ grain boundaries and rare equiaxed grains indicate that DRV is the main restoration mechanism. Typically, the microstructures after hot compressions exhibit three distinct morphology: (i) entirely recrystallized grains caused by DRX; (ii) only recovered grains caused by DRV; (iii) coexistence of recrystallized and recovered grains attribute to convolution of DRV and DRX mechanisms [14].

Fig. 14-17 displayed typical microstructures of Ti-13Nb$13 \mathrm{Zr}$ alloy after hot compression in dual phase $\alpha+\beta$ and single phase $\beta$ regions, which gave a definite information of dynamic softening behavior. Different from common circumstances, recrystallization takes place at high-temperature regimes above $\alpha / \beta$ transus, which is considered without DRX softening by Poliak-Jonas criterion[38]. All the observed microstructure evolution indicated that the softening took place by the combination of DRV and DRX, while the fraction of each one depends on deformation conditions. In each case, the $\beta$ matrix was partially retained. In addition, from Fig. 14-17, it is found that microstructures show the presence of $\alpha^{\prime}$ phase in water-quenched specimen under higher strain rate of $1-10 \mathrm{~s}^{-1}$.

As can be seen in Fig. 14-15, DRX characteristic in dual phase $\alpha+\beta$ region becomes more obvious with strain rates lowered, corresponding to the results obtained above. This is due to the fact that it is easy for DRX to occur at lower strain rates, since the dislocation density and the pile-up energy decrease at lower strain rates, and sufficient time is available for annihilation of dislocations. Further analysis of these microstructures in dual phase $\alpha+\beta$, one can find that the fraction of the recrystallized $\beta$ grain increases as deformation temperature increases. In addition to a small amount of $\alpha$ phase precipitates along the $\beta$ grain boundaries, lath-shaped intragranular $\alpha$ precipitates are formed within matrix of transformed $\beta$ grains, especially under higher strain rate of $1-10 \mathrm{~s}^{-1}$.

In single phase $\beta$ region (Fig. 16-17), it is clearly observed that the $\beta$ grains boundaries are irregular and even turn into serrated grain boundaries, which represents typical dynamic recovery characteristic. This indicates that dynamic restoration is dominated mainly by DRV at these deformation conditions. Moreover, the lower volume fraction of $\alpha$-phase at higher temperatures is the result of $\alpha$ to $\beta$ transformation. Meanwhile, Fig. $16-17 \mathrm{c}$ and $\mathrm{d}$ shows dynamically recrystallized $\beta$ grains surrounded by irregular boundaries, and also contain subgrains inside. This implies that the $\beta$ grains are formed by discontinuous DRX during deformation. As slip of dislocations and mobility of grain boundaries are the stronger in higher temperature, a num- 


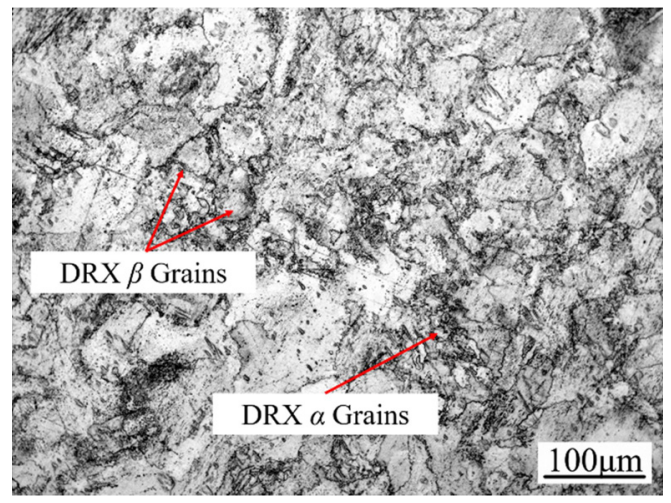

(a)

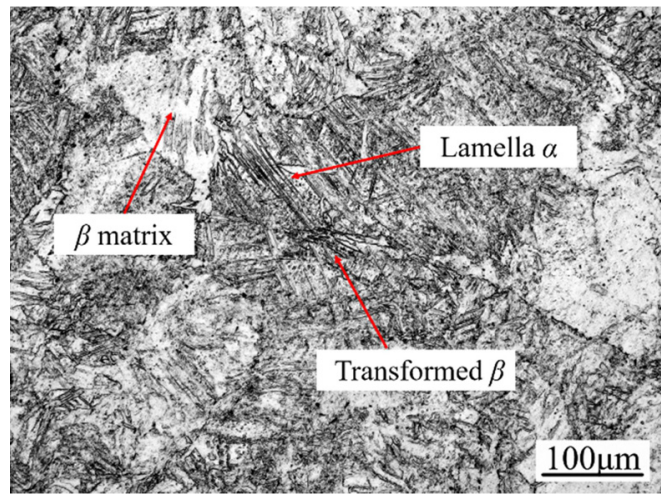

(c)

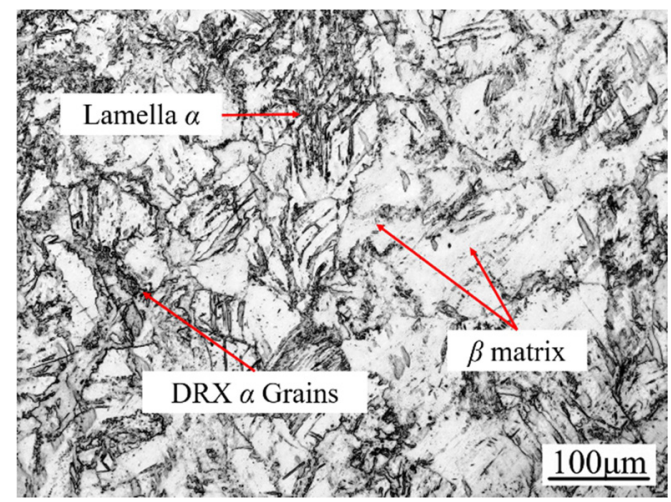

(b)

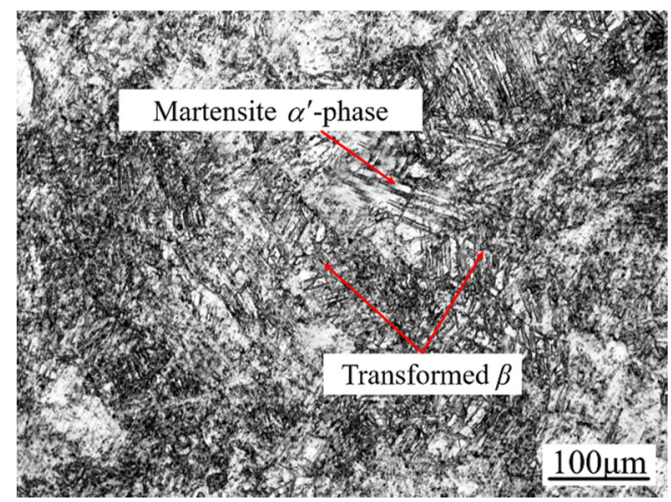

(d)

Fig. 14. Typical metallography of Ti-13Nb-13Zr alloy after isothermal compression under $923 \mathrm{~K}$ with strain rates of (a) $0.01 \mathrm{~s}^{-1}$, (b) $0.1 \mathrm{~s}^{-1}$, (c) $1 \mathrm{~s}^{-1}$, (d) $10 \mathrm{~s}^{-1}$

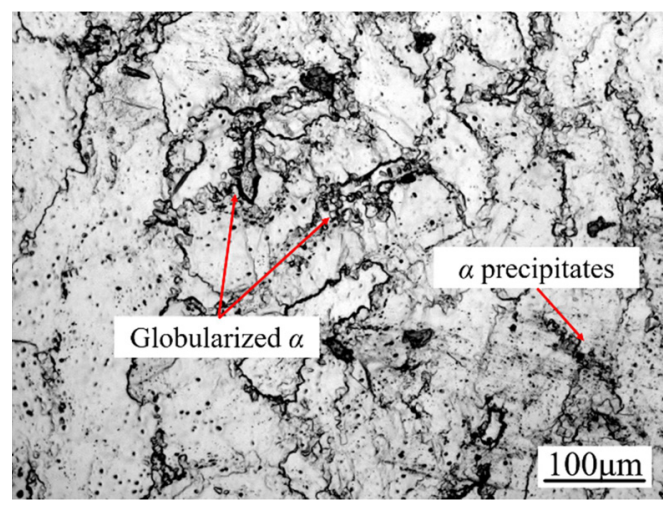

(a)

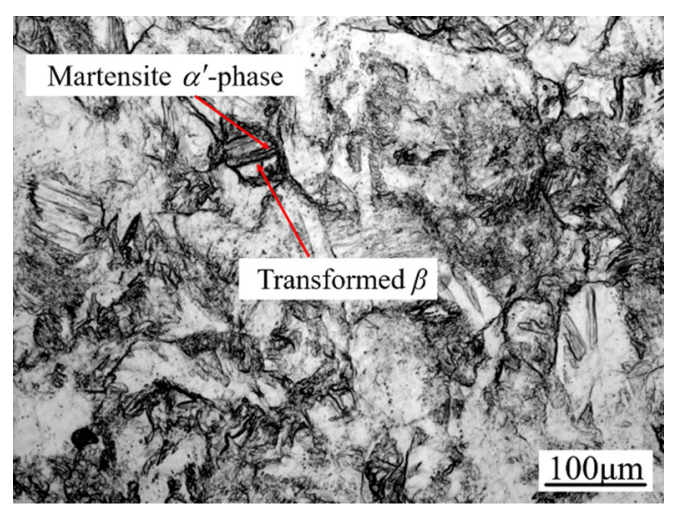

(c)

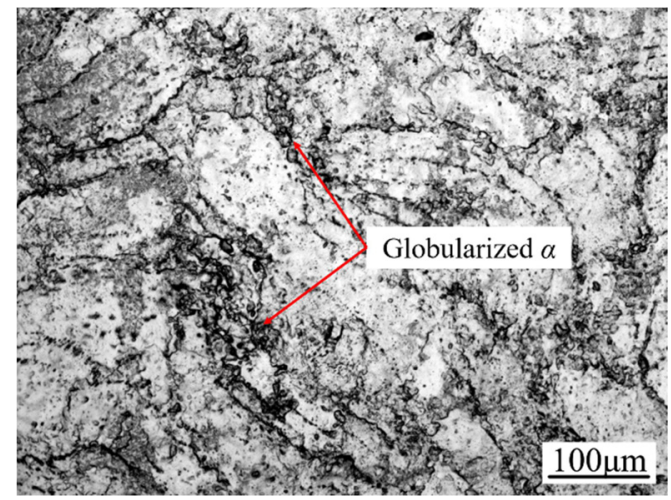

(b)

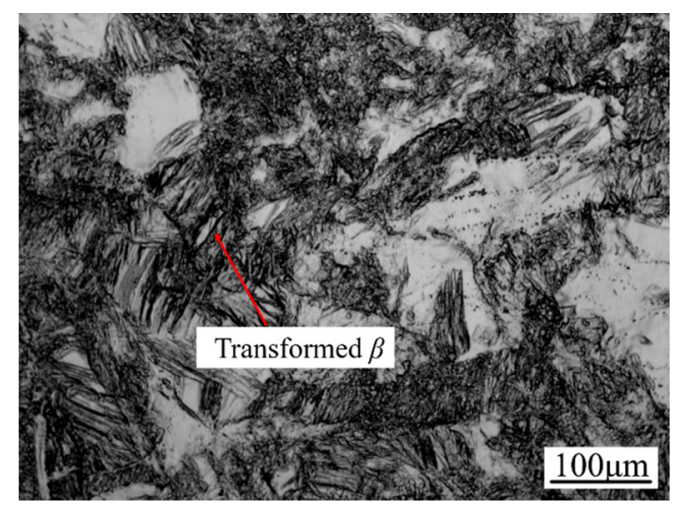

(d)

Fig. 15. Typical metallography of Ti-13Nb-13Zr alloy after isothermal compression under $973 \mathrm{~K}$ with strain rates of (a) $0.01 \mathrm{~s}^{-1}$, (b) $0.1 \mathrm{~s}^{-1}$, (c) $1 \mathrm{~s}^{-1}$, (d) $10 \mathrm{~s}^{-1}$ 


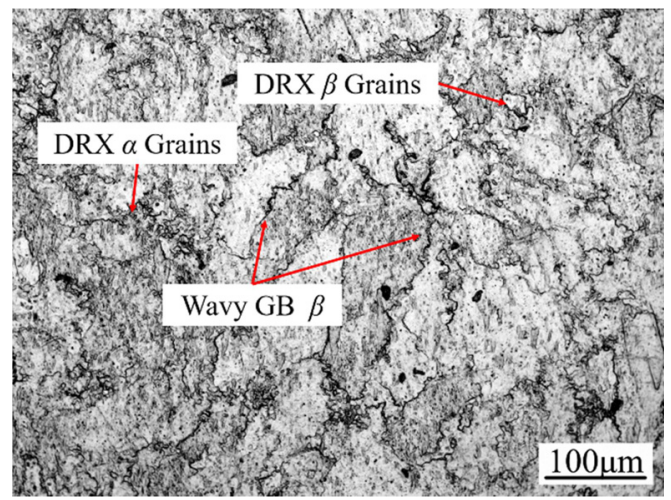

(a)

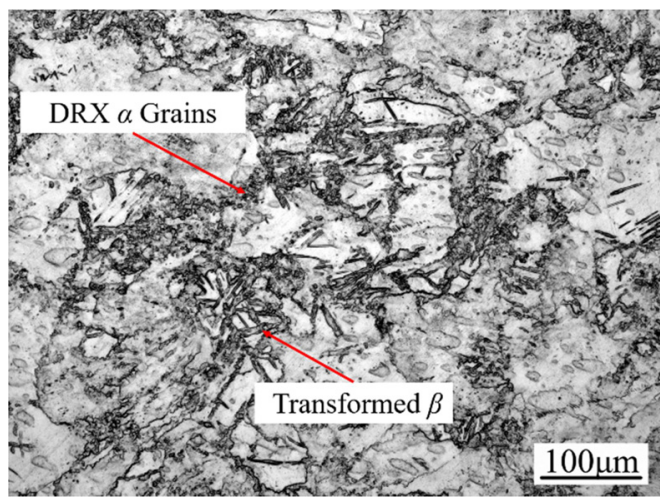

(c)

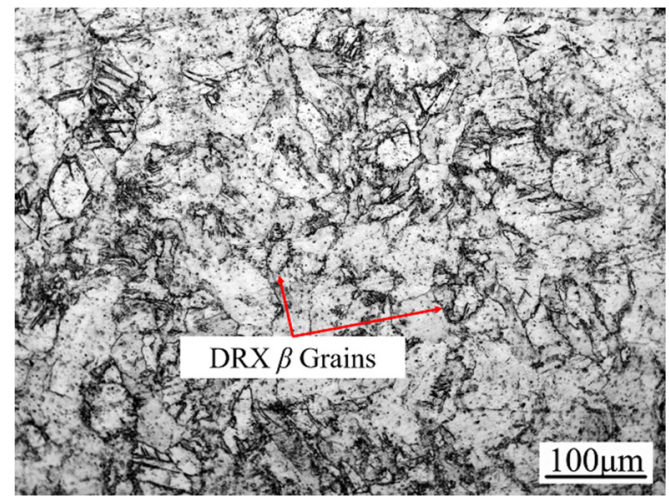

(b)

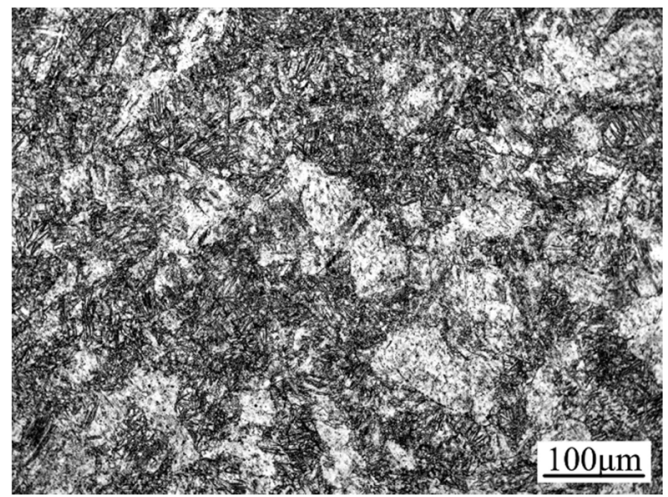

(d)

Fig. 16. Typical metallography of Ti-13Nb-13Zr alloy after isothermal compression under $1023 \mathrm{~K}$ with strain rates of (a) $0.01 \mathrm{~s}^{-1}$, (b) $0.1 \mathrm{~s}^{-1}$, (c) $1 \mathrm{~s}^{-1}$, (d) $10 \mathrm{~s}^{-1}$

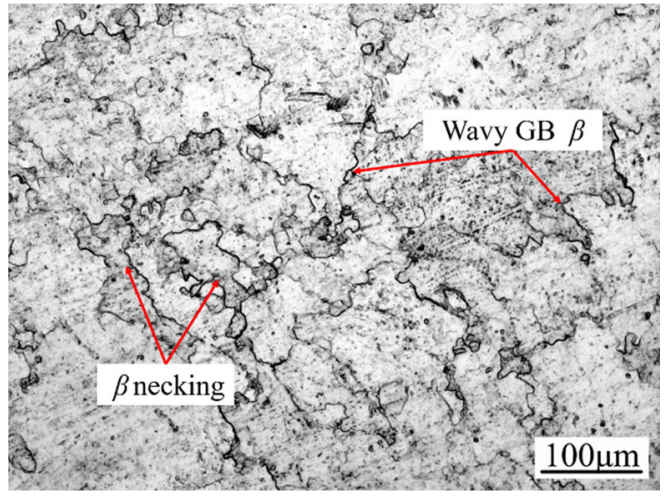

(a)

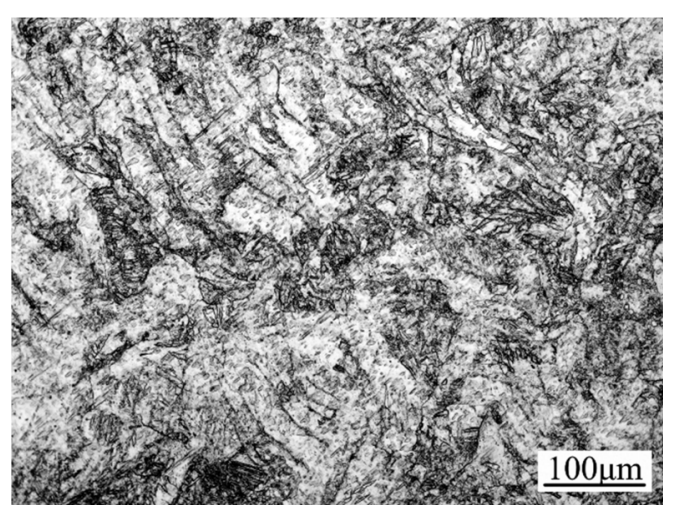

(c)

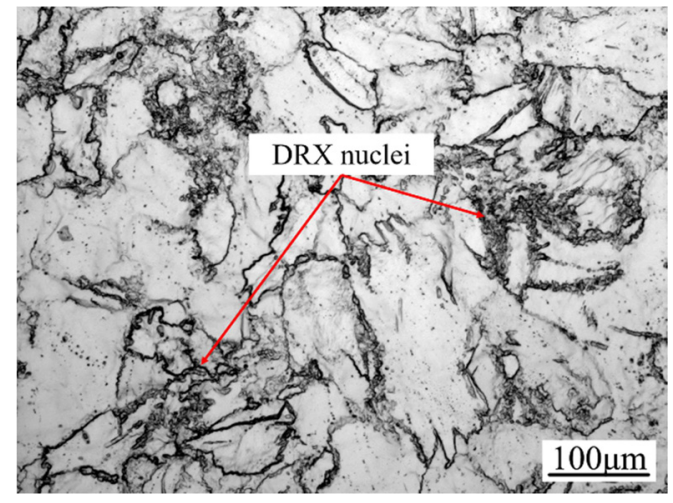

(b)

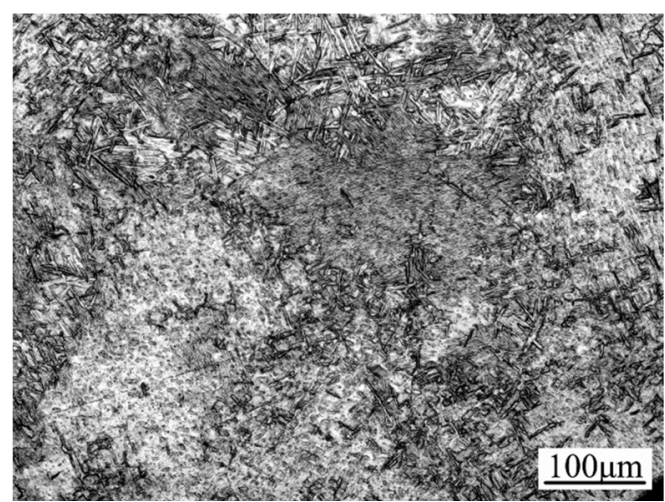

(d)

Fig. 17. Typical metallography of Ti-13Nb-13Zr alloy after isothermal compression under $1123 \mathrm{~K}$ with strain rates of (a) $0.01 \mathrm{~s}^{-1}$, (b) $0.1 \mathrm{~s}^{-1},(\mathrm{c})$ $1 \mathrm{~s}^{-1}$, (d) $10 \mathrm{~s}^{-1}$ 
ber of DRX nuclei appear in the vicinity of grain boundaries as shown in Fig. 17b.

An interesting phenomenon could be observed under temperatures above $\beta$ transus, for instance, Fig. 17a exhibited the microstructure compressed at $1123 \mathrm{~K}$ and $0.01 \mathrm{~s}^{-1}$. As arrows demonstrated, lots of necking could be identified in DRX $\beta$ grains. Similar observation was reported in the hot deformation of other titanium alloys $[8,15,21]$. This is result of the periodic competition between DRX and DRV. Multiple DRX nucleation and growth would occur but cannot achieve the complete growth and separation from deformed portion with distortion exhausted. Therefore, the necking phenomenon has been exhibited in the $\operatorname{DRX} \beta$ grains.

\section{Conclusions}

To evaluate the dynamic softening characteristics of a biomedical Ti-13Nb-13Zr Alloy, a series of hot compression tests in the temperature range of $923-1173 \mathrm{~K}$, and the strain rate range of 0.01-10 s $\mathrm{s}^{-1}$ using Gleeble-3500 thermo-mechanical physical simulator are implemented to obtain the hot flow curves and establish the DRV and DRX kinetic models,

1) Important material parameters for establishing DRV and DRX kinetic models were verified by regression analysis on the stress-strain data obtained from the hot compression tests, for instance, apparent activation energy $(Q)$, peak stress $\left(\sigma_{\mathrm{p}}\right)$, peak strain $\left(\varepsilon_{\mathrm{p}}\right)$.

2) The kinetics and fractions of DRV in single phase $\beta$ regions were determined, which are listed in Table 1. The value of the recovery parameter $(r)$ was expressed as $r=14210.8353 Z^{-0.13887}$. Using the variation of dislocation density by strain, the DRV fraction is derived as $X_{\mathrm{DRV}}=1-\exp \left(-14210.8353 Z^{-0.13887} \dot{\varepsilon} t\right)$.

3) Based on the conventional strain hardening rate curves, the dependences of the critical strain $\varepsilon_{\mathrm{c}}$ for DRX initiation on the strain for peak stress $\varepsilon_{\mathrm{p}}$ can be specified by the equation: $\varepsilon_{\mathrm{c}}=0.4804 \varepsilon_{\mathrm{p}}$, where $\varepsilon_{\mathrm{p}}$ is given by the expression: $\varepsilon_{\mathrm{p}}=0.12051 Z^{0.03381}$.

4) The kinetic models of DRX in $\alpha+\beta$-phase temperature range were developed by JMAK equation as shown in Table 2. The fraction of DRV is derived as

$$
X_{\mathrm{DRX}}=1-\exp \left[-0.5994\left(\frac{\varepsilon-\varepsilon_{\mathrm{c}}}{\varepsilon_{\mathrm{p}}}\right)^{0.9339}\right]
$$

5) The microstructures of specimens after hot compression tests were observed by optical microscope, which confirm the softening mechanisms accordingly.

\section{Acknowledgement}

The work was supported by Chongqing Foundation and Frontier Research Project (cstc2016jcyjA0335), Open Fund Project of State Key Laboratory of Materials Processing and Die \& Mould Technology (No.P2017-020), and Research Project of State Key Laboratory of Mechanical Transmission (No. SKLMT-ZZKT-2017M15).

\section{REFERENCES}

[1] H.J. Rack, J.I. Qazi, Mater. Sci. Eng. C. 26, 1269-1277 (2006).

[2] B. Arifvianto, J. Zhou, Materials 7, (2014).

[3] M. Geetha, A.K. Singh, R. Asokamani, A.K. Gogia, Prog. Mater. Sci. 54, 397-425 (2009).

[4] T. Lee, Y.-U. Heo, C.S. Lee, Scr. Mater. 69, 785-788 (2013).

[5] P. Majumdar, S.B. Singh, M. Chakraborty, J. Mech. Behav. Biomed. Mater. 4, 1132-1144 (2011).

[6] R. Bobbili, V. Madhu, J. Mech. Behav. Biomed. Mater. 59, 146155 (2016).

[7] F. Pilehva, A. Zarei-Hanzaki, S.M. Fatemi-Varzaneh, A.R. Khalesian, J. Mater. Eng. Perform. 24, 1799-1808 (2015).

[8] F. Montheillet, L. Pallot, D. Piot, Mater. Sci. Forum. 706-709, 127-134 (2012).

[9] F. Warchomicka, C. Poletti, M. Stockinger, Mater. Sci. Eng. A. 528, 8277-8285 (2011).

[10] A. Momeni, S.M. Abbasi, Mater. Des. 31, 3599-3604 (2010).

[11] T. Sakai, A. Belyakov, R. Kaibyshev, H. Miura, J.J. Jonas, Prog. Mater. Sci. 60, 130-207 (2014).

[12] R.D. Doherty, D.A. Hughes, F.J. Humphreys, J.J. Jonas, D.J. Jensen, M.E. Kassner, W.E. King, T.R. McNelley, H.J. McQueen, A.D. Rollett, Mater. Sci. Eng. A. 238, 219-274 (1997).

[13] H.S. Zurob, C.R. Hutchinson, Y. Brechet, G. Purdy, Acta Mater. 50, 3077-3094 (2002).

[14] F.J. Humphreys, M. Hatherly, Recrystallization and Related Annealing Phenomena 2nd ed, Pergamon, Oxford, United Kingdom 2004.

[15] Y.Q. Ning, X. Luo, H.Q. Liang, H.Z. Guo, J.L. Zhang, K. Tan, Mater. Sci. Eng. A. 635, 77-85 (2015).

[16] H. Mecking, U.F. Kocks, Acta Metall. 29, 1865-1875 (1981).

[17] W.F. Cui, Z. Jin, A.H. Guo, L. Zhou, Mater. Sci. Eng. A. 499, 252-256 (2009).

[18] G. Quan, S. Pu, H. Wen, Z. Zou, J. Zhou, High Temp. Mater. Processes. 34, (2015).

[19] Y.C. Lin, D.X. Wen, M.S. Chen, Y.X. Liu, X.M. Chen, X. Ma, J. Mater. Res. 31, 2415-2429 (2016).

[20] R.C. Souza, E.S. Silva, A.M. Jorge, J.M. Cabrera, O. Balancin, Mater. Sci. Eng. A. 582, 96-107 (2013).

[21] Y.Q. Ning, B.C. Xie, H.Q. Liang, H. Li, X.M. Yang, H.Z. Guo, Mater. Des. 71, 68-77 (2015).

[22] F.T. Furuhara, B. Poorganji, H. Abe, T. Maki, Jom-Us. 59, 64-67 (2007).

[23] H.J. McQueen, S. Yue, N.D. Ryan, E. Fry, J. Mater. Process. Technol. 53, 293-310 (1995).

[24] T. Furuhara, Y. Toji, H. Abe, T. Maki, Mater. Sci. Forum. 426-4, 655-660 (2003).

[25] J.J. Jonas, X. Quelennec, L. Jiang, É. Martin, Acta Mater. 57, 2748-2756 (2009).

[26] P. Wilson, Recent Developments in the Study of Recrystallization, InTech, 2013. 
[27] Y.-C. Lin, M.-S. Chen, J. Zhang, Mater. Sci. Eng. A. 499, 88-92 (2009).

[28] G.-X. Quan, G.-C. Luo, J.-T. Liang, D.-S. Wu, A. Mao, Q. Liu, Comput. Mater. Sci. 97, 136-147 (2015).

[29] G.-Z. Quan, A. Mao, G.-C. Luo, J.-T. Liang, D.-S. Wu, J. Zhou, Mater. Des. 52, 98-107 (2013).

[30] B. Dutta, E. Valdes, C.M. Sellars, Acta Metallurgica et Materialia. 40, 653-662 (1992).

[31] M.A. Mostafaei, M. Kazeminezhad, Mater. Sci. Eng., A. 544, 88-91 (2012).

[32] D. Feng, X.M. Zhang, S.D. Liu, Y.L. Deng, Mater. Sci. Eng. A. 608, 63-72 (2014).

[33] R. Zhu, Q. Liu, J. Li, S. Xiang, Y. Chen, X. Zhang, J. Alloys Compd. 650, 75-85 (2015).
[34] E.S. Puchi-Cabrera, M.H. Staia, J.D. Guérin, J. Lesage, M. Dubar, D. Chicot, Int. J. Plast. 54, 113-131 (2014).

[35] L.-X. Li, G. Wang, J. Liu, Z.-Q. Yao, T. Non Mater. Soc. 24, 42-48 (2014).

[36] L. Li, M.Q. Li, J. Luo, Mater. Sci. Eng. A. 628, 11-20 (2015).

[37] S.H. Zahiri, C.H.J. Davies, P.D. Hodgson, Scr. Mater. 52, 299-304 (2005).

[38] E.I. Poliak, J.J. Jonas, Acta Mater. 44, 127-136 (1996).

[39] A. Najafizadeh, J.J. Jonas, ISIJ Int. 46, 1679-1684 (2006).

[40] J.H. Beynon, C.M. Sellars, ISIJ Int. 32, 359-367 (1992).

[41] K.L. Wang, M.W. Fu, S.Q. Lu, X. Li, Mater. Des. 32, 1283-1291 (2011). 